\title{
Socio-economic impacts of low-carbon power generation portfolios: Strategies with and without CCS for the Netherlands
}

\author{
Barbara S. Koelbl ${ }^{\mathrm{a}, *}$, Machteld A. van den Broek ${ }^{\mathrm{a}}$, Harry C. Wilting ${ }^{\mathrm{c}}$, Mark W.J.L. Sanders ${ }^{\mathrm{b}}$, \\ Tatyana Bulavskaya ${ }^{\mathrm{d}}$, Richard Wood ${ }^{\mathrm{e}}$, André P.C. Faaij ${ }^{\mathrm{f}}$, Detlef P. van Vuuren ${ }^{\mathrm{a}, \mathrm{c}}$ \\ ${ }^{a}$ Copernicus Institute of Sustainable Development, Utrecht University, Heidelberglaan 2, 3584 CD Utrecht, The Netherlands \\ ${ }^{\mathrm{b}}$ Utrecht University School of Economics (USE), Utrecht University, Kriekenpitplein 21-22, 3584 EC Utrecht, The Netherlands \\ ${ }^{c}$ PBL Netherlands Environmental Assessment Agency, P.O. Box 303, 3720 AH Bilthoven, The Netherlands \\ ${ }^{\mathrm{d}}$ Netherlands Organisation for Applied Scientific Research (TNO), Delft 2600, The Netherlands \\ ${ }^{\mathrm{e}}$ Norwegian University of Science and Technology, Industrial Ecology Program, Høgskoleringen 5, NO-7491 Trondheim, Norway \\ ${ }_{\mathrm{f}}^{\mathrm{f}}$ Energy Academy Europe, University of Groningen, Blauwborgje 6, P.O. Box, 9700 AE Groningen, The Netherlands
}

\section{H I G H L I G H T S}

- We compare GHG mitigation policy including or excluding CCS on socio-economic impacts for the Netherlands.

- We simulate these policy options in a global multiregional Input-Output Model with detailed bottom-up technology data.

- Economy-wide differentials between these mitigation policies are small for Employment, GDP and Imports.

- Notable impacts are found for the energy sector and some upstream sectors (natural gas, construction).

- This pattern shows to base a choice on macroeconomic impacts is hard and it will affect strong and vested interests.

\section{A R T I C L E I N F O}

\section{Article history:}

Received 30 March 2016

Received in revised form 12 August 2016

Accepted 13 August 2016

\section{Keywords:}

Employment

Jobs

Power sector

Netherlands

Carbon Capture and Storage, CCS

Gross Value Added

Energy security

Trade

Greenhouse gas emission mitigation

\begin{abstract}
A B S T R A C T
Carbon Capture and Storage (CCS) could be an interesting option to mitigate greenhouse gas emissions in the Netherlands. This study compares a mitigation strategy for the Dutch power sector that includes CCS to one without on several socio-economic indicators. In particular, we calculate incremental gross value added (GVA), employment and import dependency impacts of two such low-carbon power production portfolios for the Netherlands. We combine technology specific techno-economic bottom-up data with a macro-economic multi-regional Input-Output-Table containing high sectoral detail. For the total economy, we find the differences between these scenarios to be small. Still, gross value added, and employment are lower under the CCS-inclusive strategy, while import dependency is higher. For the power sector, the differences between the scenarios are, however, considerable. Furthermore, our analysis shows that also for other sectors the differences between the scenarios could be large. For instance, a CCS-exclusive strategy leads to considerably higher GVA and employment in domestic construction services, while the CCS-inclusive strategy comes with considerably higher GVA and employment for natural gas mining and related upstream sectors.
\end{abstract}

๑) 2016 Elsevier Ltd. All rights reserved.

\section{Introduction}

The Netherlands aims to reduce greenhouse gas (GHG) emissions in 2030 by at least $40 \%$ compared to 1990 levels [1]. Recently, the Netherlands also signed the Paris Agreement on Climate Change (COP21) [2], with the overall objective to keep global temperature rise well below $2{ }^{\circ} \mathrm{C}$ and possibly even as low as $1.5^{\circ} \mathrm{C}$.

\footnotetext{
* Corresponding author at: Heidelberglaan 2, 3584 CS Utrecht, The Netherlands. E-mail address: B.S.Koelbl@uu.nl (B.S. Koelbl).
}

The energy agreement for sustainable growth for the Netherlands [3] at the same time states that fossil fuels will remain an important energy source over this period. This means that carbon capture and storage (CCS) will thus be a possible interesting technique, possibly as transition technology. Also, simply based on costs, CCS could be an attractive mitigation option in the Netherlands, given the estimated storage potential in depleted gas and oil fields for about $2.2 \mathrm{Gt}$ of $\mathrm{CO}_{2}$ [4].

The Netherlands has participated in CCS research for many years [5]. However, socio-economic impact analyses at the macro 
and sector-level are rare. Studies comparing different alternative strategies to reduce emissions are even more exceptional. A study by Koornneef et al. [6], gives a rough range of cumulative gross value added (GVA) and employment effects that could be attained by Dutch companies over the period 2010-2050. However, that study does not directly compare the implementation of CCS to a strategy relying exclusively on alternative technologies. Such a comparison of strategies with and without CCS can be found in Koopmans et al. [7], who present a cost-benefit analysis of welfare effects for these scenarios, based on key figures from existing literature. They conclude that there are no significant differences in overall cost and benefits between the two strategies for the Netherlands. While providing an interesting insight in possible aggregate socio-economic impacts of implementing CCS in the Netherlands, their study does not consider the sectoral, national and international trade interdependencies of the Netherlands.

In the present study, we implement the power production technology portfolios for the two strategies from Koopmans et al. [7] where an ambitious climate mitigation target was assumed (80\% emission reduction in 2050 compared to 1990) - and explore in more detail the socio-economic impacts of using a CCS-inclusive or renewable based strategy for the Dutch power sector. We go beyond the work by Koopmans et al. [7] by using a MultiRegional trade-linked Input-Output-Model (IO-Model). Such models allow us to gain detailed insights into the upstream economic effects at the sector-level $[8,9]$. The high sectoral detail and international trade links specified in our IO-Model, help us trace the impacts upstream through the intermediate deliveries.

Our study includes the construction of a detailed economic representation of power production in the Netherlands, consistent with plausible technological modifications until 2030. This is done by combining techno-economic data, which is country and technology specific (levelized cost of electricity (LCOE)) with the information derived for a Multi-Regional MRIO database ${ }^{1}$ to specify the projected input structure of power production in the Netherlands in 2030. Next, we calculate gross value added (GVA), employment and trade effects for a CCS-inclusive and a renewables only power production mix in the Netherlands. We compare the two scenarios based on these indicators on the aggregate as well as on the sector-level.

In this paper we contribute to the literature in three ways. In several studies the impact of CCS on GVA and employment has been assessed (e.g. [6,10-13]). However, in none of these studies CCS is considered as part of a portfolio, neither are the impacts compared to those in an alternative climate mitigation strategy. This study addresses these shortcomings.

Secondly, we compare the impact of a mitigation strategy with and without CCS for a small open economy that relies heavily on (imported) coal and gas fired power production. Earlier studies have looked at CCS in large, relatively closed economies such as the US [14], Germany [15] and China [16]. Others research indicates, however, that including CCS can have an impact on the import dependency of a country (e.g. $[17,18]$ ).

Our third contribution lies in the application of a multiregional Input-Output model for the comparison of two distinct future mitigation portfolios. In several very recent studies the IO-Method has successfully been applied to assess the impacts of gas taxes and fuel subsidies [19], feed-in tariffs [20], deployment of low-carbon technologies [21] and implementation of an energy efficiency program [22]. To the best of our knowledge this study is the first to apply this method to the diffusion of CCS in the Netherlands.

In our results, we look at the costs and benefits for specific sectors such as gas mining, fossil fuel imports, and construction. These costs (or benefits) for each sector could come in the form of lower (higher) economic activity (GVA) and lower (higher) employment. Of course the impacts on trade depend crucially on the import dependency of sectors. The results also allow us to discuss impacts on energy imports and consequently energy security. In this context, it should be noted that the Netherlands will have to reduce natural gas production anyway - and thus will have to evaluate strategies with alternative technologies or increased imports. That could make energy security an issue in the comparison as CCS relies more on fossil fuel for energy production.

Our paper proceeds as follows: In Section 2 we describe the scenarios and method used in this paper. We present our results in Section 3. Then Section 4 provides the outcomes of our sensitivity analysis. Finally, we discuss the research in Section 5 and draw conclusions in Section 6.

\section{Scenario's and methodology}

\subsection{Overall approach}

To explore economic impacts of CCS use in the power sector we calculated GVA, import dependency and employment for two potential future low-carbon power production portfolios in the Netherlands, using the Multi-Regional Input-Output database EXIOBASE. $^{2}$

The analysis consists of four steps:

\section{Scenario selection.}

2. Modification of power input vectors.

3. Scenario implementation in the Input Output-Table (IO-table) framework.

4. Calculation of economic indicators.

In step one we adopted two hypothetical scenarios for power production in the Netherlands for 2030 from Koopmans et al. [7]. Both scenarios achieve the same mitigation target in 2050. The most important difference between the scenarios is that in one CCS is excluded from the mitigation options. We chose the year 2030 because CCS can only start to play a considerable role around that time. Details about the scenarios are given in Section 2.2 below.

In step two we aggregate the EXIOBASE IO-table to three regions, (i.e. the Netherlands, remaining Europe ${ }^{3}$ and the Rest of the World (RoW)) and modify the power sector input coefficients to represent power production technologies viable in 2030. The latter are based on supplementary techno-economic cost and performance data and more details on this step are provided in Section 2.3 below.

In step three we implement the scenarios into the 2007 IOtable, by changing the output shares of different power production technologies according to the 2030 portfolio shares in the two scenarios. For this, we assume that the total sum of monetary output from power production remains constant in both scenarios. Then, we calculate the (scenario specific) final demand for power given the final demand of all other goods and services as in 2007. Our analysis thus should not be interpreted as a prediction. We show what two 2030 energy portfolios, including and excluding CCS, imply in an economy as observed in 2007. This way, we are certain that the observed effects are due to the difference in the power portfolio composition. More precisely, we use the power production portfolios developed in Koopmans et al. [7] for a hypothetical what-if analysis to provide insights into the order of magnitude of 
Table 1

Shares of technologies used for power production in the Netherlands in 2007 and in the scenarios for 2030 and 2050 . Source: Koopmans et al. [7] and CBS [27].

\begin{tabular}{|c|c|c|c|c|c|}
\hline $\begin{array}{l}\text { Power } \\
\text { production } \\
\text { technology }\end{array}$ & $\begin{array}{l}\text { Share in electricity } \\
\text { production in } 2007 \\
\text { in\% }\end{array}$ & $\begin{array}{l}\text { Share in electricity } \\
\text { production CCS-scenario } \\
\text { in } 2030 \mathrm{in} \%\end{array}$ & $\begin{array}{l}\text { Share in electricity } \\
\text { production NOCCS- } \\
\text { scenario in } 2030 \text { in } \%\end{array}$ & $\begin{array}{l}\text { Share in electricity } \\
\text { production CCS-scenario } \\
\text { in } 2050 \mathrm{in} \%\end{array}$ & $\begin{array}{l}\text { Share in electricity } \\
\text { production NOCCS- } \\
\text { scenario in } 2050 \text { in } \%\end{array}$ \\
\hline Nuclear & 4 & 7.4 & 3.4 & 16 & - \\
\hline Natural gas with CCS & - & 3.7 & - & 4 & - \\
\hline Natural gas & 58 & 47.6 & 43.3 & 24 & 24 \\
\hline Coal with CCS & - & 25.4 & - & 48 & - \\
\hline Coal & 23.4 & 2.6 & 20.2 & - & 5 \\
\hline Biomass & 3.8 & 6.8 & 8.8 & - & 3 \\
\hline Solar & 0 & 0.4 & 0.8 & 2 & 17 \\
\hline Wind energy ${ }^{a}$ & 3.3 & 6.1 & 23.5 & 6 & 51 \\
\hline Onshore & & 0.8 & 3.1 & 1 & 7 \\
\hline Offshore & & 5.3 & 20.4 & 5 & 44 \\
\hline Other & 7.4 & & & & \\
\hline
\end{tabular}

a We divide the production of wind into on and offshore wind power by using the proportions of wind power potentials estimated for the Netherlands in 2050 [4].

the macro- and sector-level differences between using the two strategies. In our analysis we assume that the economic structure remains constant over the time horizon of this study. Of course the rest of the economy will not remain constant till 2030, but here we keep all else equal to avoid confounding our results. The exact implementation strategy to keep the IO-model internally consistent is described below in Section 2.4.

Finally, in step four we calculate the impacts on economic output on all other products for both scenarios, from which the economic indicators (i.e. gross value added, employment and import dependency) are calculated and compared, respectively. This procedure is discussed in Section 2.5 below.

\subsection{Scenario selection}

We build on Koopmans et al. [7] and use the shares of two lowcarbon power production portfolios for the Netherlands in 2030 from their study. Koopmans et al. [7] developed their scenarios as follows: First, they projected energy demand and economic development for the Netherlands by adapting the $\mathrm{WLO}^{4}$ scenario Strong Europe $[23,24]$. For international data they used the assumptions in the IEA Blue Map scenario [25]. In the analysis, global economic growth was assumed to be $3.3 \%$ p.a., while for the Netherlands a growth rate of $1.6 \%$ was assumed [7]..$^{5}$ The Strong Europe scenario in the WLO (CPB et al. $[23,24])$ assumes a carbon price of 58 euro/ $\mathrm{tCO}_{2}$ and Koopmans et al. [7]'s assumptions about the oil, gas and coal prices were summarized in their Table 3.1. Subsequently, Koopmans et al. [7] defined the potential energy savings and the corresponding final energy use. Based on this, they determine different possible production mixes under the constraint of a reduction in greenhouse gases of $80 \%$ in 2050 compared to 1990 levels. ${ }^{6}$

Among the alternatives for the energy transition in the Netherlands they compared a "fossil-fuel-based" and a "renewablebased" route. The "fossil-fuel-based" scenario relies more heavily on fossil fuels but in combination with CCS. Also, more nuclear power is assumed in the CCS scenario. In contrast, the "renewable-based" scenario assumes that CCS is not an option and that the most important energy sources are renewable technologies. We simply adopted these scenarios and call them the CCS-scenario and the NOCCS-scenario, respectively.

For both scenarios the final energy use is assumed the same and amounts to roughly $3100 \mathrm{PJ}$ in 2030 [7]. Also, total electricity production develops equallyin the two scenarios. The technology

\footnotetext{
${ }^{4}$ Welvaart en leefomgeving (WLO).

5 This assumption is based on the scenario Strong Europe in CPB et al. [24] and is similar to the prognosis in OECD [75].

${ }^{6}$ An overview table with assumptions can be found in Koopmans et al. [7]
}

mix suggested by Koopmans et al. [7] is not a direct outcome of an optimization or simulation exercise. The technology mix in each alternative scenario in Koopmans et al. [7] was constructed based on scenario specific assumptions about the availability of technologies, technology potentials and learning curves based on Schoots [26].

Koopmans et al. [7] assume that international action in mitigating GHG emissions is taking place as in the Blue Map scenario of the IEA [25] and the Strong Europe scenario in the WLO [24]. The international context is important as assuming international emission reduction action reduces the costs for the Netherlands due to enhanced technical development and economies of scale [see 7]. Koopmans et al. [7] assume subsidies and an emission trading scheme (ETS) for the promotion of low-carbon technologies.

Notably, we assume the same carbon price of 58 euro/ $\mathrm{tCO}_{2}$ for the CCS and the NOCCS scenario although the IEA [25] study shows that the marginal cost increases from $115 €_{2010} / \mathrm{tCO}_{2}$ to $192 €_{2010} /$ $\mathrm{tCO}_{2}{ }^{7}$ if CCS is not an option in 2050. The reason is that we follow the approach of Koopmans et al. [7] and want to take the international context as given. This assumption can be justified as changing the strategy between using and not using CCS in the Netherlands is very unlikely to affect the European $\mathrm{CO}_{2}$ price.

The technology shares in the power production portfolio of the two scenarios adapted for the Netherlands are shown in Table 1. The most important technology in 2030 in both scenarios is natural gas without $\mathrm{CO}_{2}$ capture. The reason for the dominant role of this technology, also in the future, is that Koopmans et al. [7] assume this technology will continue to be used for peak demand. In the NOCCS scenario coal without $\mathrm{CO}_{2}$ capture still makes up $20 \%$ of the portfolio. In contrast, most of the coal in the CCS scenario is used in combination with CCS and makes up one quarter of the CCS scenario portfolio. Carbon capture with fossil fuels is not an option in the NOCCS scenario but Koopmans et al. [7] expect offshore wind power to become competitive from 2030 onwards. The share of wind power in the NOCCS scenario thus makes up more than $20 \%$ and reaches a mere $6 \%$ in the CCS scenario. Also, somewhat more biomass cofiring is used in the NOCCS scenario compared to the CCS scenario. Finally, nuclear power is used more in the CCS scenario (7\%).

We tested the robustness of our results using the shares for 2050. These are also displayed in Table 1 . As can be seen, natural gas without capture still plays a large role in both portfolios (24\%), while coal without capture is phased out in the CCS portfolio and plays a minor role in the NOCCS scenario (5\%). The major share of power production in the NOCCS portfolio is power from wind (51\%) while also solar power was assumed to become competitive by 2050 (17\%). In the CCS scenario CCS achieves most of the CO2

\footnotetext{
$7175 \mathrm{USD}_{2008}$ to $293 \mathrm{USD}_{2008} / \mathrm{tCO}_{2}[25]$.
} 
Table 2

LCOE for the Netherlands in 2030.

\begin{tabular}{|c|c|c|c|c|c|c|c|c|c|c|c|}
\hline \multirow{2}{*}{$\begin{array}{l}\text { In } €_{2010} / \mathrm{MW} \mathrm{h} \\
\text { Type of plant }\end{array}$} & \multicolumn{2}{|c|}{$\begin{array}{l}\text { Combined } \\
\text { cycle }\end{array}$} & \multicolumn{2}{|c|}{ Pulverization } & \multicolumn{2}{|c|}{ Combined cycle } & \multirow[b]{2}{*}{$\begin{array}{l}\text { Biomass } \\
\text { co-firing }^{\text {a }}\end{array}$} & \multirow[b]{2}{*}{ Nuclear } & \multirow[b]{2}{*}{$\begin{array}{l}\text { Onshore } \\
\text { wind }\end{array}$} & \multirow[b]{2}{*}{$\begin{array}{l}\text { Offshore } \\
\text { wind }\end{array}$} & \multirow[b]{2}{*}{$\begin{array}{l}\text { Solar } \\
\text { PV }\end{array}$} \\
\hline & Coal & $\begin{array}{l}\text { Coal } \\
\text { CCS }\end{array}$ & Coal & $\begin{array}{l}\text { Coal } \\
\text { CCS }\end{array}$ & $\begin{array}{l}\text { Natural } \\
\text { gas }\end{array}$ & $\begin{array}{l}\text { Natural } \\
\text { gas CCS }\end{array}$ & & & & & \\
\hline Investment per year (excluding interest) & 6.9 & 9.2 & 5.2 & 8.0 & 3.3 & 5.5 & 11.6 & 7.3 & 21.4 & 22.1 & 51.6 \\
\hline $\begin{array}{l}\text { Interest over lifetime + Interest during } \\
\text { construction divided over lifetime }\end{array}$ & 21.3 & 28.4 & 16.1 & 24.6 & 7.2 & 11.9 & 20.3 & 36.7 & 37.6 & 38.8 & 90.6 \\
\hline $\mathrm{O} \& \mathrm{M}$ & 7.3 & 10.1 & 5.6 & 7.9 & 2.9 & 3.9 & 7.5 & 8.2 & 7.1 & 12.9 & 18.8 \\
\hline Fuel cost & 28.2 & 32.6 & 28.8 & 34.2 & 57.5 & 64.8 & 39.6 & 6.1 & 0.0 & 0.0 & 0.0 \\
\hline $\mathrm{CO}_{2} \operatorname{tax}$ & 38.2 & 4.4 & 38.9 & 4.6 & 18.9 & 2.1 & 11.4 & 0.0 & 0.0 & 0.0 & 0.0 \\
\hline $\mathrm{CO}_{2}$ transport & 0.0 & 0.8 & 0.0 & 0.8 & 0.0 & 0.4 & 0.0 & 0.0 & 0.0 & 0.0 & 0.0 \\
\hline $\mathrm{CO}_{2}$ storage & 0.0 & 4.9 & 0.0 & 5.1 & 0.0 & 2.4 & 0.0 & 0.0 & 0.0 & 0.0 & 0.0 \\
\hline Total LCOE & 101.9 & 90.4 & 94.6 & 85.2 & 89.7 & 90.9 & 90.4 & 58.4 & 66.1 & 73.8 & 161.0 \\
\hline
\end{tabular}

\section{Assumptions:}

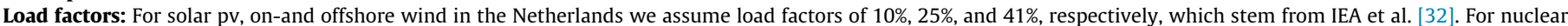

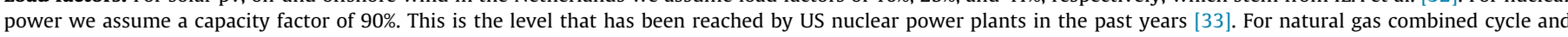

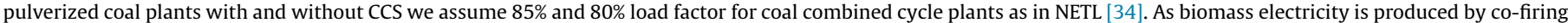
we assume the same load factor for biomass as for a coal fired plant without CCS.

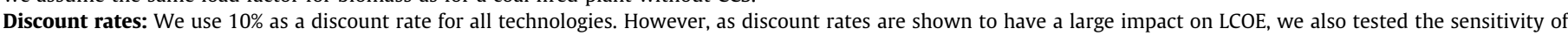

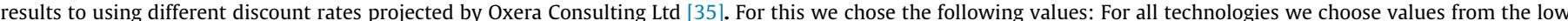

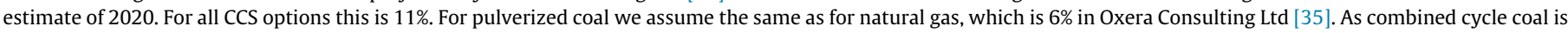

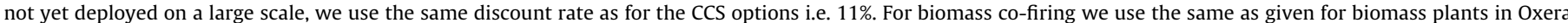

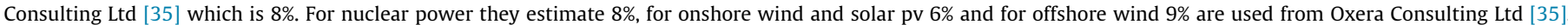

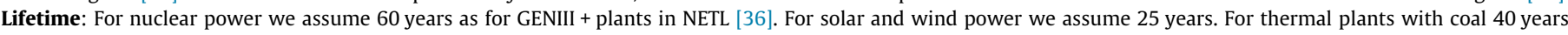
while natural gas plants have an assumed lifetime of 30 years as in IEA et al. [32]. For biomass co-firing power we assume a lifetime of 25 years [37].

Fuel cost: See Table 4.

Carbon price: $58 \mathrm{EurO}_{2010} / \mathrm{tCO}_{2}[38]$.

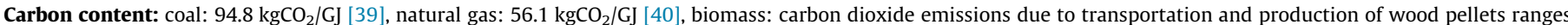
between 7 and $28 \mathrm{kgCO}_{2}$-eq/GJ [41] for this analysis we use the upper value of the range.

Energy content fuel: Natural gas $38.1 \mathrm{MJ} / \mathrm{kg}$ (LHV, daf) [40], coal 31.84 (LHV, daf) [39], biomass 19.4 MJ/kg (LHV, daf)[42].

Capture rate for CCS plants: $90 \%$ [34].

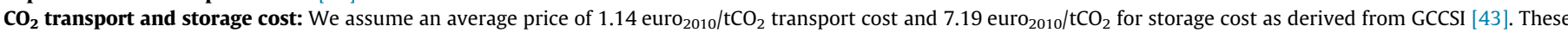
values are within the range of cost estimated for different storage types in van den Broek et al. [44].

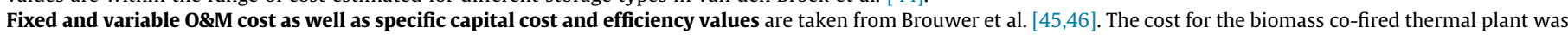

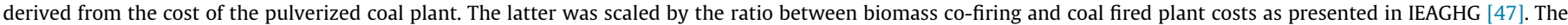

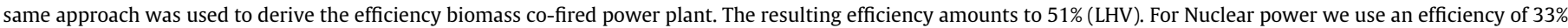
as in IEA [48].

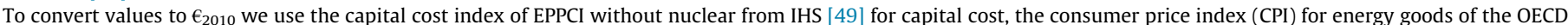
region [50].

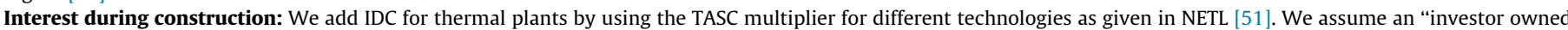

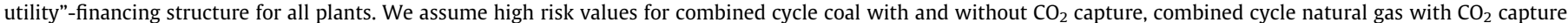

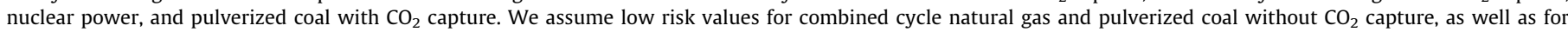
biomass fired power plants. The TASC value for IGCC, IGCC-CCS, PC-CCS, biomass and nuclear power is 1.14 , for PC 1.134 , for NGCC 1.075 and for NGCC-CCS 1.078 [51].

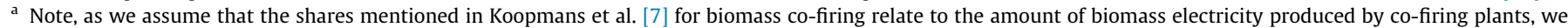
calculate the fuel price solely based on the biomass price.

abatement in combination with coal (48\%), and nuclear power (16\%), while renewable power makes up only $8 \%$ of the total portfolio.

\subsection{Modification of power input vectors in EXIOBASE}

The power production in EXIOBASE version 2.2.2 consists of 12 separately specified input vectors, each of which represents a different power production technology in 2007. These input vectors were created prior to this research by disaggregating the energy sector of the supply and use tables that form the basis for the EXIOBASE input output database (see Wood et al. [28-30]). In this research, we replace these input vectors for power production in the Netherlands such that the input coefficients represent the power production options used in 2030 according to the scenarios discussed above. We do this exclusively for the input vectors representing power production in the Netherlands. There are no changes for the other sectors or regions. The major changes to the input vectors of the power sector involve:

- The change of input coefficients based on the cost shares (Tables 2 and 3) of levelized cost of electricity (LCOE) for the (2007) Dutch power sector that is already in the model. This LCOE was calculated for power production in 2030 and includes a carbon price of $58 € / \mathrm{tCO}_{2}$, consistent with the assumption in Koopmans et al. [7] and CPB et al. [23,24]. The cost shares are used to adjust the input coefficients representing the supply of products, services and primary inputs (e.g. labor costs) to the production of power with different technologies. We use the LCOE from a consistent set of techno-economic data for all power technologies. This reduces possible bias introduced from the disaggregation process of power production in EXIOBASE.

- The addition of input vectors representing power production with Carbon Capture and Storage (CCS) for natural gas and coal in 2030.

- The distinction of two types of wind power production (onshore and offshore wind) $)^{8}$ as this sector was represented as one aggregate input vector in EXIOBASE.

- The internalization of the capital cost for power production for all technologies. This means that we distribute the investment cost share over intermediate inputs, instead of accounting for this share as part of the value added account as usually done

\footnotetext{
${ }^{8}$ For wind EXIOBASE contains only one input vector. We use the LCOE shares for on and offshore wind to create two separate input vectors which are based on the aggregate input vector of EXIOBASE.
} 
Table 3

Assumptions to create input vectors representing 2030 power technologies in the Netherlands.

\begin{tabular}{|c|c|c|c|c|c|c|c|}
\hline $\begin{array}{l}\text { LCOE } \\
\text { component }\end{array}$ & $\begin{array}{l}\text { Integrated coal } \\
\text { gasification combined } \\
\text { cycle and pulverized } \\
\text { coal }\end{array}$ & Combined cycle natural gas & $\begin{array}{l}\text { On/ } \\
\text { Offshore } \\
\text { Wind }^{\mathrm{a}} \& \\
\text { Solar PV }\end{array}$ & Nuclear & Biomass co-firing & $\begin{array}{l}\text { Integrated coal } \\
\text { gasification combined } \\
\text { cycle/ pulverized coal } \\
\text { with CCS }\end{array}$ & Combined cycle natural gas with CCS \\
\hline Investment cost & \multicolumn{5}{|c|}{$\begin{array}{l}\text { Distributed over intermediate inputs based on disaggregated version of capital cost matrix from a European study of } 2050 \text { in Koelbl } \\
\text { et al. [31] } \\
\text { For biomass the capital cost distribution of the biomass/waste power option in this study was used } \\
\text { Import shares per product are based on import shares in the A-matrix of EXIOBASE } \\
\text { Note: The investment cost distribution is only done for intermediate inputs and hence does not contain value added components such } \\
\text { as wages. These are only accounted for on the second production layer. (E.g. wages paid for constructing the power plant are note } \\
\text { accounted for as a direct primary input in the power sector but as an input to the construction sector that supplies to the power } \\
\text { sector.) }\end{array}$} & \multicolumn{2}{|c|}{$\begin{array}{l}\text { Scaled the capital cost vector of the respective non-CCS option by } \\
\text { the ratio between CCS and non-CCS options of the capital cost } \\
\text { breakdown which was created with a similar sector detail in Koelbl } \\
\text { et al. [31] for advanced power options }\end{array}$} \\
\hline $\begin{array}{l}\text { Capital financing } \\
\text { cost }^{\mathrm{c}}\end{array}$ & \multicolumn{7}{|c|}{ Treated as "remaining net operating profit" } \\
\hline $\begin{array}{l}\text { Operation and } \\
\text { maintenance }\end{array}$ & \multicolumn{5}{|c|}{$\begin{array}{l}\text { Distributed over primary inputs (value added accounts) and intermediate inputs by using the distribution of input coefficients of the } \\
\text { A-matrix and VA-account in EXIOBASE the respective technologies } \\
\text { Note: we exclude for the cost shares which are treated separately. In particular, coefficients linking the power sector to fuel providing } \\
\text { sector and pipeline transport } \\
\text { Import shares per product are based on import shares in the A-matrix of EXIOBASE }\end{array}$} & \multicolumn{2}{|c|}{$\begin{array}{l}\text { Scaled the A-matrix input vector of the respective non-CCS option } \\
\text { by the ratio between CCS and non-CCS options of the A-matrix } \\
\text { breakdown created in Koelbl et al. [31] for advanced power options } \\
\text { of Europe. Import shares per product are based on import shares in } \\
\text { the A-matrix of EXIOBASE }\end{array}$} \\
\hline Fuel cost & $\begin{array}{l}\text { Distributed to "coal } \\
\text { mining/extraction" } \\
\text { proportionally to the } \\
\text { EXIOBASE input } \\
\text { coefficients for coal } \\
\text { power } \\
\text { Import shares are } \\
\text { based on the shares as } \\
\text { in EXIOBASE }\end{array}$ & $\begin{array}{l}\text { Distributed to "gas extraction services" } \\
\text { and "distribution services of gaseous } \\
\text { fuels through mains" and to "pipeline } \\
\text { transport" according to the proportions } \\
\text { in the EXIOBASE database } \\
\text { Import shares are based on the shares } \\
\text { as in EXIOBASE }\end{array}$ & n.a. & $\begin{array}{l}\text { Distributed } \\
\text { to nuclear } \\
\text { fuel } \\
\text { production } \\
\text { Import } \\
\text { shares are } \\
\text { based on } \\
\text { the shares } \\
\text { as in } \\
\text { EXIOBASE }\end{array}$ & $\begin{array}{l}\text { For biomass co-firing we assume the } \\
\text { use of wood pellets/wood waste and } \\
\text { paper only. Therefore, domestic } \\
\text { biomass supply is assumed to come } \\
\text { from wood products sector } \\
\text { Import shares are based on the } \\
\text { shares as in EXIOBASE }\end{array}$ & $\begin{array}{l}\text { Distributed to "coal } \\
\text { mining/extraction". } \\
\text { proportionally to the } \\
\text { EXIOBASE input } \\
\text { coefficients for coal } \\
\text { power } \\
\text { Import shares are } \\
\text { based on the shares as } \\
\text { in EXIOBASE }\end{array}$ & $\begin{array}{l}\text { Distributed to "gas extraction services" } \\
\text { and "distribution services of gaseous } \\
\text { fuels through mains" and to "pipeline } \\
\text { transport services" according to the } \\
\text { proportions in the EXIOBASE database } \\
\text { Import shares are based on the shares as } \\
\text { in EXIOBASE }\end{array}$ \\
\hline Carbon price & \multicolumn{2}{|c|}{ Treated as other taxes on production } & n.a. & & \multicolumn{3}{|l|}{ Treated as other taxes on production } \\
\hline Transport cost & \multicolumn{5}{|c|}{ n.a. } & \multicolumn{2}{|c|}{$\begin{array}{l}\text { Distribution over primary and intermediate inputs according to the } \\
\text { same proportions as in the "Transportation services via pipelines" } \\
\text { sector in EXIOBASE. Import shares per product are based on import } \\
\text { shares in the A-matrix of EXIOBASE }\end{array}$} \\
\hline Storage cost & \multicolumn{5}{|l|}{ n.a. } & \multicolumn{2}{|c|}{$\begin{array}{l}\text { Distribution over primary and intermediate inputs according to the } \\
\text { average proportions of the coal, petroleum and natural gas mining/ } \\
\text { extraction in EXIOBASE. Import shares per product are based on } \\
\text { import shares in the A-matrix of EXIOBASE }\end{array}$} \\
\hline
\end{tabular}


in Input-Output Tables. This allows us to make a fair comparison between the technologies as some have significantly larger shares of capital cost. Accounting for capital expenditures on intermediary goods and services allows us to account for upstream impacts of capital-intensive power production, which would be cut off on the first production layer otherwise. It is important to note that the distribution of capital cost over intermediate supplies is only done for the power sector (see Koelbl et al. [31]). If one or the other scenarios involved higher upstream investments (e.g. a wind farm Construction Company buying an extra crane), those effects are ignored. We internalize capital expenditure in the 2007 table before implementing the scenario specific changes. We approximated the distribution of consumed capital over supplying sectors by making use of capital cost matrix from a European study of 2050 in Koelbl et al. [31] and subtracted the internalized capital consumption from the respective capital formation in the final demand vector of 2007.

We then turn to the new input vectors and proceed in two steps. First, we calculated the LCOEs of the 11 different power production technologies in Table 2 and allocate the costs to five main categories (see first column of Table 3). Projected technology specific investment, operation and maintenance (O\&M) and performance values for power production in the Netherlands in 2030 are mostly based on Brouwer et al. $[45,46]$. The assumed fuel prices are given in Table 4 and we took the projected employment coefficients for power production in the Netherlands from Koelbl et al. [31] (which are provided in the supplementary material of this article).

Then, we disaggregated these LCOE categories by distributing them over the 200 products and 3 regions of the IO-table. Table 3 lists the assumptions made in the process of this disaggregation.

The aggregated input vectors are then shown in Fig. 1 below (on and offshore wind and Combined Cycle coal and Pulverized coal are not presented separately resulting in 8 technologies). These show that operating surplus ${ }^{9}$ is higher for renewable plants because of higher capital cost and higher capital financing requirements. Technologies with higher capital cost need to achieve higher operating surplus to recuperate their higher financing cost. Moreover, renewable plants have higher inputs from construction services and advanced manufacturing (e.g. machinery, fabricated metal products $)^{10}$ compared to other power plant types. Both are a result of the higher capital cost per $\mathrm{kW} \mathrm{h}$ and higher input shares of these products per euro of output. Taxes - mostly consisting of the carbon price - are highest for coal-fired power and very low for carbon capture and storage plants as most of the $\mathrm{CO}_{2}$ is not emitted. Inputs from mining are high for coal and natural gas fired power as this sector provides the fuel inputs. Finally, for biomass power, fuel is supplied mostly from wood production.

To show how the changes described in this section are implemented in the IO-table context we provide Fig. 2 which illustrates the EXIOBASE data table before (a) and after (b) the modification of the power input vectors by means of an example with 4 products and 3 power technologies. (Fig. 2(c) shows the modifications made

\footnotetext{
${ }^{9}$ Operating surplus is a residual value of the value added account after subtracting wages and salaries, taxes less subsidies on production and imports [76,77]. In EXIOBASE it is split into operating surplus from: consumption of fixed capital, rents on land, royalties and remaining net operating surpluses. We treat financing cost of capital (see Table 3 ) as remaining net operating surplus within the framework of the IO-table.

${ }^{10}$ Advanced manufacturing includes machinery and equipment, office machinery, computers, electrical machinery and apparatus, radio, television and communication equipment and apparatus, medical, precision and optical instruments, watches and clocks, motor vehicles, trailers and semi-trailers, other transport equipment, furniture and secondary raw materials.
}

Table 4

Fuel price assumptions for 2030.

\begin{tabular}{ll}
\hline Fuel type & $€_{2010} / \mathrm{GJ}$ \\
\hline Coal $^{\mathrm{a}}$ & 4.08 \\
Gas $^{\mathrm{a}}$ & 9.90 \\
Uranium $^{\mathrm{b}}$ & 0.56 \\
Biomass $^{\mathrm{c}}$ & 7.66 \\
\hline
\end{tabular}

For the conversion of prices to $€_{2010}$ we use the CPI for energy goods in OECD regions [55] and USD/Euro exchange rates from [56].

Sources:

a Verdonk and Wetzels [38].

b IEA [32] including cost for uranium mining, milling, conversion, enrichment, fuel fabrication, and spent fuel transport, storage, processing and disposal.

c We use the price of wood pellets including cost for transport and storage for the Netherlands as given in Londo et al. [52]. This is similar to the average price for wood pellets reported in [53]. The weighted average price for 2030 calculated from Elbersen et al. [54] given the potentials for wood and paper based biomass, amount to $4.3 €_{2010} /$ GJ-primary. However, these costs are "road side" cost and thus are lower.

to implement the scenarios, which is described in the next section). The red ${ }^{11}$ dashed square contains the intermediate input coefficients (a) (forming matrix $\mathbf{A}$ ), the black dashed rectangle illustrates the value added coefficients (va) (forming row vector va). Final demand $(\mathrm{fd})^{12}$ (forming column vector $\mathbf{f d}$ ) is illustrated in the green rectangle and output ( $\mathrm{x}$ ) (forming column vector $\mathbf{x}$ ) in the black rectangle.

The table is disaggregated into different products (in this example $\mathrm{p} 1, \ldots, \mathrm{p} 4)$; while $\mathrm{p} 1$ is power production disaggregated into the different power production technologies (in this example $\mathrm{p} 1=\mathrm{e} 1, \mathrm{e} 2, \ldots, \mathrm{e} 3$ ) (we depict power as the first product (p1) in the IO-table for convenience of illustrating).

Grey shaded areas contain intermediate input coefficients to power production, forming the sub-matrices

$$
\mathbf{A}_{\mathbf{e}, \mathbf{e}}=\left[\begin{array}{ccc}
a_{e 1, e 1} & \cdots & a_{e 1, e 3} \\
\vdots & \ddots & \vdots \\
a_{e 3, e 1} & \cdots & a_{e 3, e 3}
\end{array}\right] \text { and } \mathbf{A}_{\mathbf{p}, \mathbf{e}}=\left[\begin{array}{ccc}
a_{p 2, e 1} & \cdots & a_{p 2, e 3} \\
\vdots & \ddots & \vdots \\
a_{p 4, e 1} & \cdots & a_{p 4, e 3}
\end{array}\right]
$$

the input coefficients of power to production of other products (non-electricity) forming the sub-matrix

$$
\mathbf{A}_{\mathbf{e}, \mathbf{p}}=\left[\begin{array}{ccc}
a_{e 1, p 2} & \cdots & a_{e 1, p 4} \\
\vdots & \ddots & \vdots \\
a_{e 3, p 2} & \cdots & a_{e 3, p 4}
\end{array}\right]
$$

value added inputs to power production (forming the row subvector $\mathbf{v a}_{\mathbf{e}}=\left[v a_{e 1}, \ldots, v a_{e 3}\right]$ ), final demand (forming the column sub-vector $\mathbf{f d}_{\mathbf{e}}=\left[f d_{e 1}, \ldots, f d_{e 3}\right]^{\mathbf{T}}$ where ${ }^{\mathbf{T}}$ denotes transposition), and output of power production (forming the column sub-vector $\left.\mathbf{x}_{\mathbf{e}}=\left[x_{e 1}, \ldots, x_{e 3}\right]^{\mathbf{T}}\right)$.

White areas are the input coefficients of non-electricity products to non-electricity products forming the matrix

$$
\mathbf{A}_{\mathbf{p}, \mathbf{p}}=\left[\begin{array}{ccc}
a_{p 2, p 2} & \cdots & a_{p 2, p 4} \\
\vdots & \ddots & \vdots \\
a_{p 4, p 2} & \cdots & a_{p 4, p 4}
\end{array}\right]
$$

and value added inputs to non-electricity products (forming the row sub-vector $\mathbf{v a}_{\mathbf{p}}=\left[v a_{p 2}, \ldots, v a_{p 4}\right]$ ), final demand (forming the column sub-vector $\left.\mathbf{f d}_{\mathbf{p}}=\left[f d_{p 2}, \ldots, f d_{p 4}\right]^{\mathbf{T}}\right)$, and total output of

\footnotetext{
${ }^{11}$ For interpretation of color in Fig. 2, the reader is referred to the web version of this article.

12 All final demand categories were added up to one final demand column.
} 


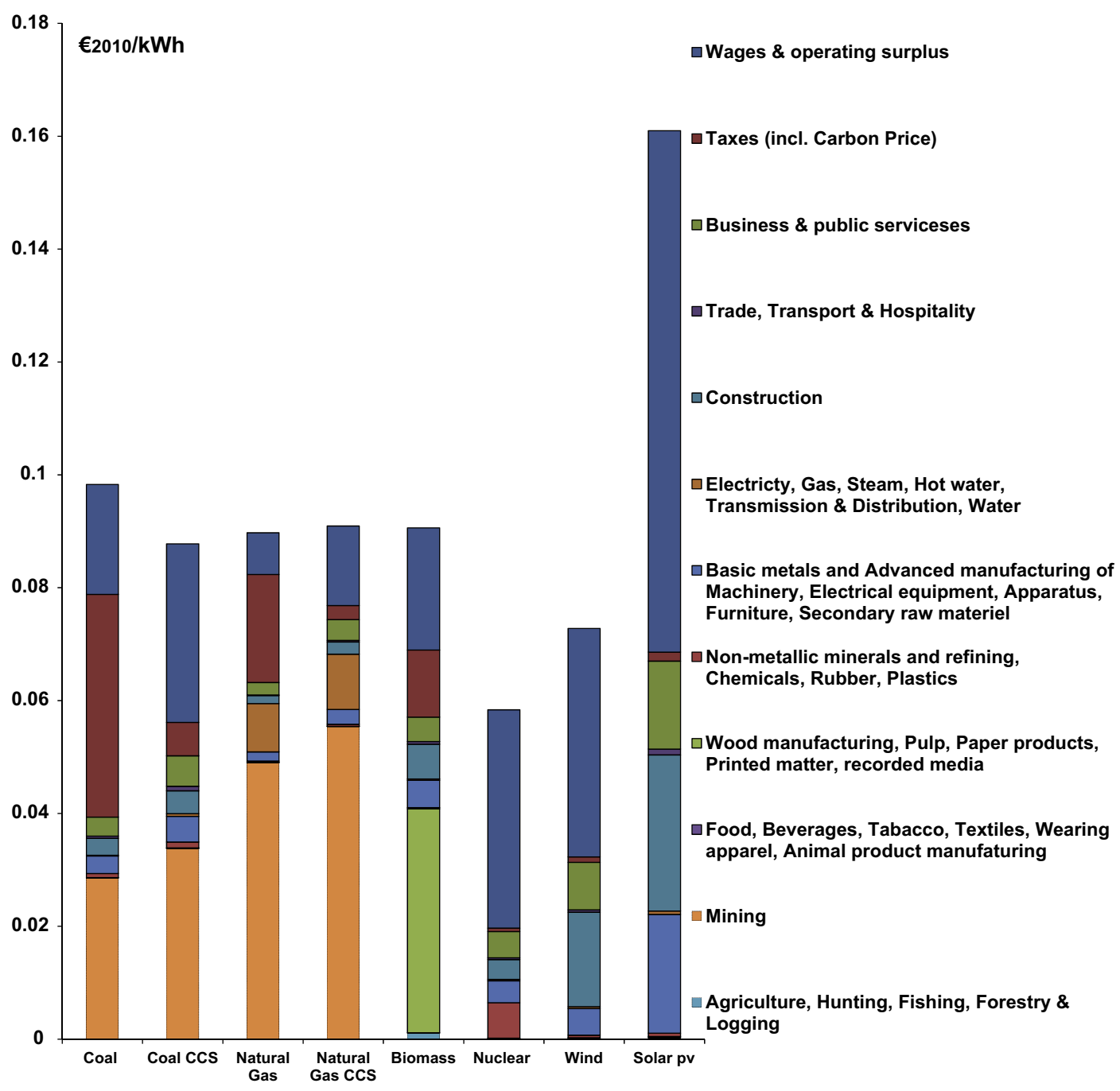

Fig. 1. Aggregated input vectors for power production constructed from LCOE for 2030 (for assumptions see also supplementary material).

non-electricity production (forming the column sub-vector $\left.\mathbf{x}_{\mathbf{p}}=\left[x_{p 2}, \ldots, x_{p 4}\right]^{\mathbf{T}}\right)$.

Fig. 2(b) shows the changes made to the A-matrix, and value added coefficients of the EXIOBASE data after implementing the modifications to the power sector inputs. Here, we replaced the input coefficients for electricity production $\mathbf{A}_{\mathbf{p}, \mathbf{e}}, \mathbf{A}_{\mathbf{e}, \mathbf{e}}$ and $\mathbf{v a} \mathbf{a}_{\mathbf{e}}$ by the input coefficients constructed in this Section, $\mathbf{A}_{\mathbf{p}, \mathbf{e}}^{\prime}, \mathbf{A}_{\mathbf{e}, \mathbf{e}}^{\prime}$ and, $\mathbf{v a}_{\mathbf{e}}^{\prime}$ (where' denotes the modified sub-matrix/sub-vector). $\mathbf{A}_{\mathbf{p}, \mathbf{e}}^{\prime}$, $\mathbf{A}_{\mathbf{e}, \mathbf{e}}^{\prime}$ and $\mathbf{v a} \mathbf{a}_{\mathbf{e}}^{\prime}$ contain modified coefficients according the cost structure for the different electricity production technologies as shown in Fig. 1 and described in Table 3. Input coefficients for the different technologies in $\mathbf{A}_{\mathbf{p}, \mathbf{e}}^{\prime}, \mathbf{A}_{\mathbf{e}, \mathbf{e}}^{\prime}$, and $\mathbf{v a} \mathbf{a}_{\mathbf{e}}^{\prime}$, are the same in both scenarios as LCOE are assumed to be the same in both scenarios.

In the following section we describe how we implement the scenarios in the IO-table framework as illustrated in Fig. 2(c). The scenario specific changes affect the rows of the A-Matrix depicting the intermediate power supply coefficients for the Netherlands (denoted by sub-matrix $\mathbf{A}_{\mathbf{e}, \mathbf{p}, \mathbf{s}}^{\prime}$ and $\mathbf{A}_{\mathbf{e}, \mathbf{e}, \mathbf{s}}^{\prime}$ where $\mathrm{s}=$ \{CCS scenario; NOCCS scenario\}), the output of power production per technology (denoted by sub-vector $\mathbf{x}_{\mathbf{e}, \mathbf{s}}^{\prime}$ ) and the derivation of final demand (denoted by $\mathbf{f d}_{\mathbf{e} . \mathbf{s}}^{\prime}$ ) per power technology for each scenario. Finally, we show how the resulting output for all other products (denoted by $\mathbf{x}_{\mathbf{p}, \mathbf{s}}^{\prime}$ ) is calculated and in Section 2.5 the calculation of the indicators is described.

\subsection{Scenario implementation in the IO-table framework}

To implement the different technology shares of the electricity production in the IO-table framework, we take the following main steps (which are further elaborated below):

(1) First, we calculate the technology shares (s) in electricity supply to determine the coefficients for intermediate electricity supply $\left(\mathbf{A}_{\mathbf{e}, \mathbf{p}, \mathbf{s}}^{\prime}, \mathbf{A}_{\mathbf{e}, \mathbf{e}, \mathbf{s}}^{\prime}\right)$ and the division of monetary output of electricity per technology $\mathbf{x} / \mathbf{e}, \mathbf{s}$ in the Netherlands.

(2) Second, keeping total monetary output of electricity in the IOtable (for the Netherlands) constant (i.e. the sum of all elements in $\mathbf{x}_{\mathbf{e}, \mathbf{s}}^{\prime}$ equals the sum of all elements in $\mathbf{x}_{\mathbf{e}}$ ), we calculate the corresponding final demand for electricity for each scenario $\mathbf{f d}_{\mathbf{e}, \boldsymbol{s}}^{\prime}$.

(3) Third, we use the final demand for electricity calculated in the previous step $\mathbf{f d}_{\mathbf{e}, \mathbf{s}}^{\prime}$ and the final demand for nonelectricity goods of the IO-table from $2007\left(\mathbf{f d}_{\mathbf{p}}\right)$ and calculate the output of all other products and services in all (domestic and foreign) regions $\mathbf{x}_{\mathbf{p}, \mathbf{s}}^{\prime}$ (other than the Dutch electricity production). We can then use the output to calculate the impacts on employment, GVA and imports and compare them between the scenarios.

(1) We calculate the share(s) of each power technology in the total monetary value of electricity production as: 
(a)

\begin{tabular}{|c|c|c|c|c|c|c|c|c|c|}
\hline \multirow{2}{*}{\multicolumn{2}{|c|}{ A }} & \multicolumn{3}{|c|}{ Product 1 (Electricity) } & \multirow{2}{*}{$\begin{array}{l}\text { Product } \\
2\end{array}$} & \multirow{2}{*}{ Product 3} & \multirow{2}{*}{$\begin{array}{l}\text { Product } \\
4\end{array}$} & \multirow{2}{*}{$\begin{array}{l}\text { Final } \\
\text { demand }\end{array}$} & \multirow{2}{*}{ Output } \\
\hline & & $\begin{array}{l}\text { Technology } \\
\text { e1 }\end{array}$ & Technology e2 & Technology e3 & & & & & \\
\hline \multirow{3}{*}{$\begin{array}{l}\text { Produ } \\
\text { ct } 1 \\
\text { (Elect } \\
\text { ricity) }\end{array}$} & \multirow{3}{*}{$\begin{array}{l}\text { Technol } \\
\text { ogy e1 } \\
\text { Technol } \\
\text { ogy e2 } \\
\text { Technol } \\
\text { ogy e3 }\end{array}$} & $a_{e 1, e 1}$ & $a_{\mathrm{e} 1, \mathrm{e} 2}$ & $a_{\mathrm{e} 1, \mathrm{e} 3}$ & $a_{\mathrm{e} 1, p 2}$ & $a_{e 1, p 3}$ & $a_{e 1, p 4}$ & $f d_{e 1}$ & $x_{e 1}$ \\
\hline & & $a_{e 2, e 1}$ & $a_{e 2, e 2}$ & $a_{\mathrm{e} 2, \mathrm{e} 3}$ & $a_{e 2, p 2}$ & $a_{e 2, p 3}$ & $a_{e 2, p 4}$ & $f d_{\mathrm{e} 2}$ & $x_{e 2}$ \\
\hline & & $a_{e 3, e 1}$ & $a_{\mathrm{e} 3 \mathrm{e} 2}$ & $a_{\mathrm{e} 3 \mathrm{e}, 3}$ & $a_{e 3, p 2}$ & $a_{e 3, p 3}$ & $a_{e 3, p 4}$ & $f d_{\mathrm{e} 3}$ & $x_{e 3}$ \\
\hline \multicolumn{2}{|c|}{ Product 2} & $a_{p 2, \mathrm{e} 1}$ & $a_{p 2, e 2}$ & $a_{p 2, \mathrm{e} 3}$ & $a_{p 2, p 2}$ & $a_{p 2, p 3}$ & $a_{p 2, p 4}$ & $f d_{p 2}$ & $x_{p 2}$ \\
\hline \multirow{2}{*}{\multicolumn{2}{|c|}{$\begin{array}{l}\text { Product } 3 \\
\text { Product } 4\end{array}$}} & $a_{p 3, \mathrm{e} 1}$ & $a_{p 3, \mathrm{e} 2}$ & $a_{p 3, \mathrm{e} 3}$ & $a_{p 3, p 2}$ & $a_{p 3, p 3}$ & $a_{p 3, p 4}$ & $f d_{p 3}$ & $x_{p 3}$ \\
\hline & & $a_{p 4, \mathrm{e} 1}$ & $a_{p 4, \mathrm{e} 2}$ & $a_{p 4, \mathrm{e} 3}$ & $a_{p 4, p 2}$ & $a_{p 4, p 3}$ & $a_{p 4, p 4}$ & $f d_{p 4}$ & $x_{p 4}$ \\
\hline \multicolumn{2}{|c|}{$\begin{array}{l}\text { Value added } \\
\text { coefficients }\end{array}$} & $v a_{e 1}$ & $v a_{e 2}$ & $v a_{\mathrm{e} 3}$ & $v a_{p 2}$ & $v a_{p 3}$ & $v a_{p 4}$ & & \\
\hline
\end{tabular}

(b)

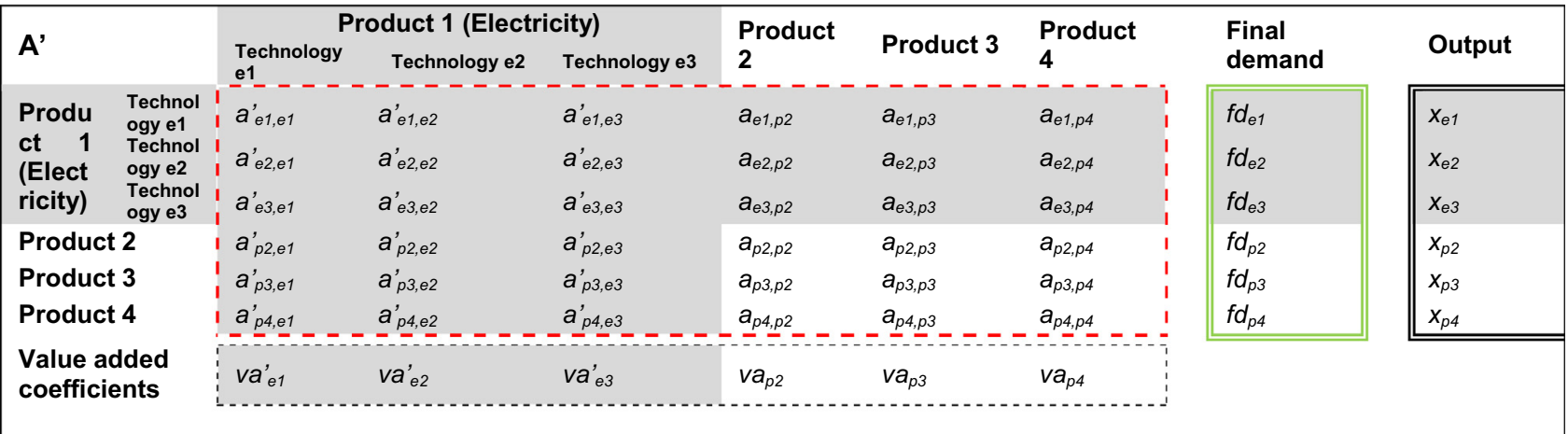

(c)

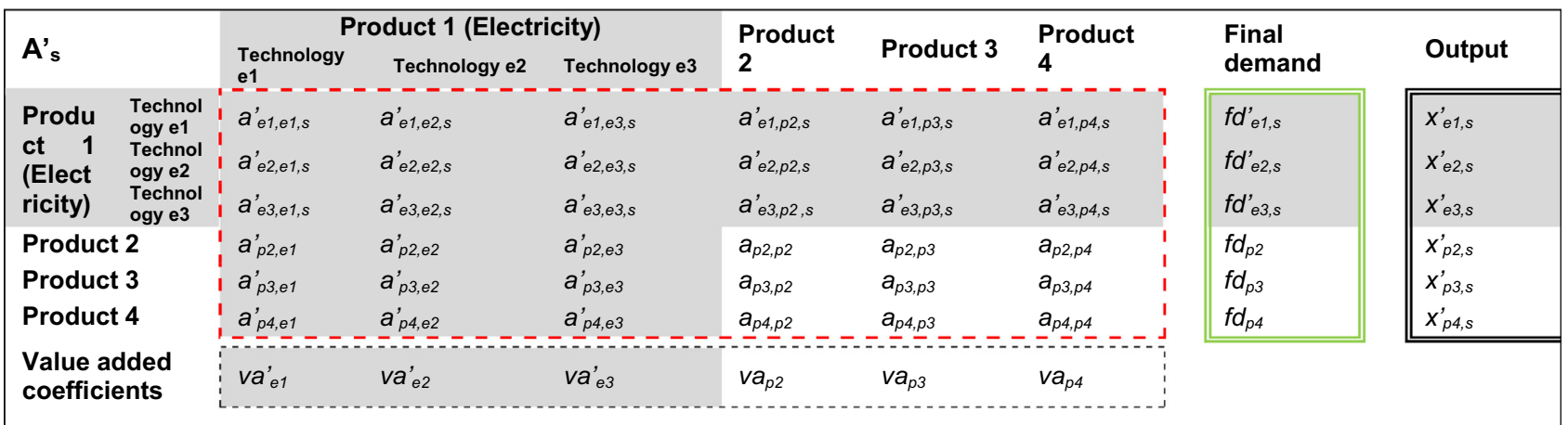

Fig. 2. A-matrix, value added coefficients, final demand and output before (a), and after implementing the modified power input coefficients (b) and the scenarios (c).

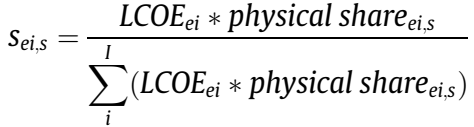

$\mathrm{ei}=\{\mathrm{e} 1 \ldots \mathrm{e} 3\} ; \mathrm{I}=3$ no. of power technologies; $\sum_{e i=1}^{I} S_{e i, s}=1$; subscript $\mathrm{s}=\{$ CCS scenario; NOCCS scenario $\}$;

Physical shares of each power option are based on Koopmans et al. [7] (see Table 1) and the LCOE are shown in Table 2 (see table notes for sources and assumptions). ${ }^{13}$ The shares are then used to (re-)distribute the coefficients depicting the intermediate electricity supply by Dutch power plants in the model $\left(\mathbf{A}_{\mathbf{e}, \mathbf{p}, \mathbf{s}}^{\prime}, \mathbf{A}_{\mathbf{e}, \mathbf{e}, \mathbf{s}}^{\prime}\right)$. The modified coefficients are then calculated for each scenario(s):

\footnotetext{
$\overline{13}$ By using the whole LCOE value to calculate the monetary value of electricity production per generator, we assume that all costs are regained, including investment cost and cost to finance the capital.
}

$a_{e i, p n, s}^{\prime}=\left(\sum_{e i=1}^{I} a_{e i, p n}\right) * s_{e i, s}$

ei $=\{\mathrm{e} 1 \ldots \mathrm{e} 3\} ; \mathrm{I}=3$ no. of power technologies; $\mathrm{pn}=\{\mathrm{p} 2 \ldots \mathrm{p} 4\}$; $\sum_{e i=1}^{I} S_{e i, s}=1$;

subscript $s=\{$ CCS scenario; NOCCS scenario $\}$;

and

$a_{e i, e j, s}^{\prime}=\left(\sum_{e i=1}^{I} a_{e i, e j}^{\prime}\right) * s_{e i, s}$

$\left.{ }^{14} \mathrm{ei}=\{\mathrm{e} 1 \ldots \mathrm{e}\}\right\} ; \mathrm{I}=3$ no. of power technologies; $\mathrm{ej}=\{\mathrm{e} 1 \ldots \mathrm{e} 3\}$; $\sum_{e i=1}^{I} S_{e i, s}=1$;

\footnotetext{
${ }^{14}$ Note: the coefficients $a_{e i, e j}^{\prime}$ of submatrix $A_{e, e}^{\prime}$ have been altered also when implementing the new input structure for power production technologies. Here, they are further altered to distribute the inputs of power to power production per technology according to the scenario shares of power production. Therefore, $a_{e i, e j}^{\prime}$ changes to $a_{e i, e j, s .}^{\prime}$
} 
subscript s = \{CCS scenario; NOCCS scenario $\}$;

The new A-Matrix, is shown in Fig. 2c). $\mathbf{A}^{\prime}{ }_{\mathbf{s}}$ consists of a modified electricity sector. The input coefficients for intermediate inputs from electricity production to electricity production and to all other products are represented by scenario specific sub-matrices $\left(\mathbf{A}_{\mathbf{e}, \mathbf{e}, \mathbf{s}}^{\prime}\right.$ and $\left.\mathbf{A}_{\mathbf{e}, \mathbf{p}, \mathbf{s}}^{\prime}\right)$, which change with the scenario according to $\mathrm{s}_{\mathrm{ei}}$ s. The modified input coefficients to electricity production $\left(\mathbf{A}_{\mathbf{p}, \mathbf{e}}^{\prime}\right)$ are the same for the CCS and the NOCCS scenario. The nonelectricity input coefficients $\left(\mathbf{A}_{\mathbf{p . p}}\right)$ remain the same as in the original A-matrix in both scenarios. Together they constitute the modified A-matrix:

$\mathbf{A}_{\mathbf{s}}^{\prime}=\left[\begin{array}{cc}\mathbf{A}_{\mathbf{e}, \mathbf{e}, \mathbf{s}}^{\prime} & \mathbf{A}_{\mathbf{e}, \mathbf{p}, \mathbf{s}}^{\prime} \\ \mathbf{A}_{\mathbf{p}, \mathbf{e}}^{\prime} & \mathbf{A}_{\mathbf{p}, \mathbf{p}}\end{array}\right]$

Subsequently, total monetary output (x) for electricity production (e) is re-distributed according to these shares as well. Such that the total output of electricity production add up to the same amount before and after introducing the scenarios (i.e. monetary output of electricity production is kept constant in both scenarios). Output of each power technology $\left(\mathbf{x}_{\mathbf{e} . \mathbf{s}}^{\prime}=\left[x_{e 1, s}^{\prime}, \ldots, x_{e 3, s}^{\prime}\right]^{T}\right)$, is thus determined for each scenario as:

$x_{e i, s}^{\prime}=\left(\sum_{e i=1}^{I} x_{e i}\right) * S_{e i, s}$

ei $=\{$ e1 . . e3 $\} ;$ I = 3 no. of power technologies; $\sum_{e i=1}^{I} S_{e i, s}=1$; subscript $\mathrm{s}=\{$ CCS scenario; NOCCS scenario $\}$;

(2) Next, we calculate final demand for electricity for each scenario (s) $\left(\mathbf{f d}_{\mathbf{e} . \mathbf{s}}^{\prime}=\left[f d_{e 1, s}^{\prime}, \ldots, f d_{e 3, s}^{\prime}\right]^{\mathbf{T}}\right)$, while we keep total monetary output of electricity $\left(\sum_{e i=1}^{I} x_{e i, s}\right)$ constant. For this we introduce the following method, using the Leontief model (see Leontief $[57,58])$ :

$\mathbf{x}=(\mathbf{I}-\mathbf{A})^{-1} \mathbf{f d}$

Total output for each scenario $\left(\mathbf{x}_{\mathbf{s}}\right)$ is:

$$
\left\lceil\begin{array}{c}
\mathbf{x}_{\mathbf{e}, \mathbf{s}}^{\prime} \\
\mathbf{X}_{\mathbf{p}, \mathbf{s}}^{\prime}
\end{array}\right]=\left(\mathbf{I}-\left[\begin{array}{cc}
\mathbf{A}_{\mathbf{e}, \mathbf{e}, \mathbf{s}}^{\prime} & \mathbf{A}_{\mathbf{e}, \mathbf{p}, \mathbf{s}}^{\prime} \\
\mathbf{A}_{\mathbf{p}, \mathbf{e}}^{\prime} & \mathbf{A}_{\mathbf{p}, \mathbf{p}}
\end{array}\right]\right)^{-1} *\left[\begin{array}{c}
\mathbf{f d}_{\mathbf{e}, \mathbf{s}}^{\prime} \\
\mathbf{f d}_{\mathbf{p}}
\end{array}\right]
$$

Defining the Leontief inverse:

$$
\left(\mathbf{I}-\left[\begin{array}{cc}
\mathbf{A}_{\mathbf{e}, \mathbf{e}, \mathbf{s}}^{\prime} & \mathbf{A}_{\mathbf{e}, \mathbf{p}, \mathbf{s}}^{\prime} \\
\mathbf{A}_{\mathbf{p}, \mathbf{e}}^{\prime} & \mathbf{A}_{\mathbf{p}, \mathbf{p}}
\end{array}\right]\right)^{-1}=\left[\begin{array}{cc}
\mathbf{L}_{\mathbf{e}, \mathbf{e}, \mathbf{s}} & \mathbf{L}_{\mathbf{e}, \mathbf{p}, \mathbf{s}} \\
\mathbf{L}_{\mathbf{p}, \mathbf{e}} & \mathbf{L}_{\mathbf{p}, \mathbf{p}}
\end{array}\right]
$$

and inserting in the equation above:

$$
\left\lceil\begin{array}{l}
\mathbf{x}_{\mathbf{e}, \mathbf{s}}^{\prime} \\
\mathbf{x}_{\mathbf{p}, \mathbf{s}}^{\prime}
\end{array}\right]=\left[\begin{array}{cc}
\mathbf{L}_{\mathbf{e}, \mathbf{e}, \mathbf{s}} & \mathbf{L}_{\mathbf{e}, \mathbf{p}, \mathbf{s}} \\
\mathbf{L}_{\mathbf{p}, \mathbf{e}} & \mathbf{L}_{\mathbf{p}, \mathbf{p}}
\end{array}\right] *\left[\begin{array}{c}
\mathbf{f d}_{\mathbf{e}, \mathbf{s}}^{\prime} \\
\mathbf{f d}_{\mathbf{p}}
\end{array}\right]
$$

Then, we assume that final demand from the 2007 IO-table for all non-electricity products $\left(\mathbf{f d}_{\mathbf{p}}\right)$ remains the same as in 2007 (i.e. producing the same quantity of final demand for goods and services (except for electricity) as in 2007 but use different power technologies). As we keep the total monetary electricity output constant, we know all elements of $\mathbf{x}_{\mathbf{e} s}^{\prime}$, and thus there are 3 equations with 3 unknowns for final demand of electricity:

$\mathbf{x}_{\mathbf{e}, \mathbf{s}}^{\prime}=\mathbf{L}_{\mathbf{e}, \mathbf{e}, \mathbf{s}} * \mathbf{f d}_{\mathbf{e}, \mathbf{s}}^{\prime}+\mathbf{L}_{\mathbf{e}, \mathbf{p}, \mathbf{s}} * \mathbf{f d}_{\mathbf{p}}$

Solving for the electricity demand of final demand per scenario and technology $\mathbf{f d}_{\mathbf{e}}^{\prime}$

$\mathbf{f d}_{\mathbf{e}, \mathbf{s}}^{\prime}=\left[\mathbf{L}_{\mathbf{e}, \mathbf{e}, \mathbf{s}}\right]^{-1} *\left[\mathbf{x}_{\mathbf{e}, \mathbf{s}}^{\prime}-\mathbf{L}_{\mathbf{e}, \mathbf{p}, \mathbf{s}} * \mathbf{f d}_{\mathbf{p}}\right]$
(3) Once we have $\mathbf{f d}_{\mathbf{e}, \mathbf{s}}^{\prime}$ we can solve for the remaining new output $\mathbf{x}_{\mathbf{p} . \mathbf{s}}^{\prime}$ for the respective scenarios ( $\mathbf{x}_{\mathbf{c c s}}^{\prime}$ and $\mathbf{x}_{\text {Noccs }}^{\prime}$ ), by solving the Leontief equation $(5 b)$ for each scenario:

$\mathbf{x}_{\mathbf{c C S}}^{\prime}=\left\lceil\begin{array}{l}\mathbf{x}_{\mathbf{e}, \mathrm{ccs}}^{\prime} \\ \mathbf{x}_{\mathbf{p}, \mathrm{ccs}}^{\prime}\end{array}\right]=\left[\begin{array}{cc}\mathbf{L}_{\mathbf{e}, \mathbf{e}, \mathrm{ccs}} & \mathbf{L}_{\mathbf{e}, \mathbf{p}, \mathrm{ccs}} \\ \mathbf{L}_{\mathbf{p}, \mathbf{e}} & \mathbf{L}_{\mathbf{p}, \mathbf{p}}\end{array}\right] *\left[\begin{array}{c}\mathbf{f d}_{\mathbf{e}, \mathrm{ccs}}^{\prime} \\ \mathbf{f d}_{\mathbf{p}}\end{array}\right]$

and

$\mathbf{x}_{\text {NOCCS }}^{\prime}=\left[\begin{array}{c}\mathbf{x}_{\mathbf{e}, \text { NOCCS }}^{\prime} \\ \mathbf{x}_{\mathbf{p}, \text { NOCCS }}^{\prime}\end{array}\right]=\left[\begin{array}{cc}\mathbf{L}_{\mathbf{e}, \mathbf{e}, \text { NOCCS }} & \mathbf{L}_{\mathbf{e}, \mathbf{p}, \text { NOCCS }} \\ \mathbf{L}_{\mathbf{p}, \mathbf{e}} & \mathbf{L}_{\mathbf{p}, \mathbf{p}}\end{array}\right] *\left[\begin{array}{c}\mathbf{f d}_{\mathbf{e}, \text { NOCCS }}^{\prime} \\ \mathbf{f d}_{\mathbf{p}}\end{array}\right]$

From this we can calculate the balanced IO-table for each scenario containing the new supply structures between sectors and regions (see Malik et al. [59]) where “^” means diagonalization:

$\mathbf{Z}_{\mathrm{CCS}}^{\prime}=\mathbf{A}_{\mathrm{CCS}}^{\prime} * \widehat{\mathbf{x}_{\mathrm{CCS}}^{\prime}}$

and

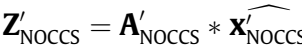

where $\mathrm{Z}$ is the matrix of intermediate products, $\mathrm{A}$ is the matrix of intermediate input coefficients and $\mathrm{x}$ is the vector of outputs.

\subsection{Calculation of economic indicators}

Intermediate imports are obtained from the off-diagonals of $\mathbf{Z}_{\mathrm{ccs}}^{\prime}$ and $\mathbf{Z}_{\text {Noccs}}^{\prime}$, while we obtain GVA and employment by the Gross Value Added (gva) and employment (empl) intensity per unit of output (x), where gva and empl are row vectors and $\mathbf{x}$ is a column vector:

$\mathrm{GVA}_{\mathrm{CCS}}=\mathbf{g v a} * \mathbf{x}_{\mathrm{CCS}}^{\prime}$

$\mathrm{GVA}_{\mathrm{NOCCS}}=\mathbf{g v a} * \mathbf{x}_{\mathrm{NOCCS}}^{\prime}$

and

$\mathrm{EMPL}_{\mathrm{CCS}}=\mathbf{e m p l} * \mathbf{x}_{\mathrm{CCS}}^{\prime}$

$\mathrm{EMPL}_{\mathrm{NOCCS}}=\mathbf{e m p l} * \mathbf{x}_{\mathrm{NOCCS}}^{\prime}$

The results are then evaluated by taking the difference between the CCS and the NOCCS scenario results $\mathbf{G V A}_{\mathrm{CCS}}-\mathbf{G V A}_{\mathrm{NO}}$, $\mathbf{E M P L}_{\mathrm{CCS}}-\mathbf{E M P L}_{\mathrm{NOCCS}}$ and similarly for total imports. To assess the economic significance of the differences and to review the differences in context, we express the total differences and the sector differences as a percentage of the respective GVA, employment and import levels from the original 2007 IO-table.

\section{Results}

In this section we first present the differences we have assumed between the two scenarios. Then, the domestic impacts on employment and GVA are described for the macro- and sector level. Finally, we discuss how the impacts on trade differ between the two scenarios and conclude this section.

\subsection{Technology mix in the two scenarios}

Fig. 3 shows the technology shares $\left(s_{e i, C C S}\right.$ and $\left.s_{e i, N O C C S}\right)$ in total monetary power output of the two scenarios as implemented into the EXIOBASE IO-tables calculated by Eq. (4) in Section 2.4. ${ }^{15}$ As can be seen, renewable technologies have higher shares in total monetary power output in the NOCCS scenario while the fossil fueled thermal power plants and nuclear power make up for more

\footnotetext{
15 Note, as the shares are calculated from monetary values, they differ somewhat from the shares in Table 1.
} 


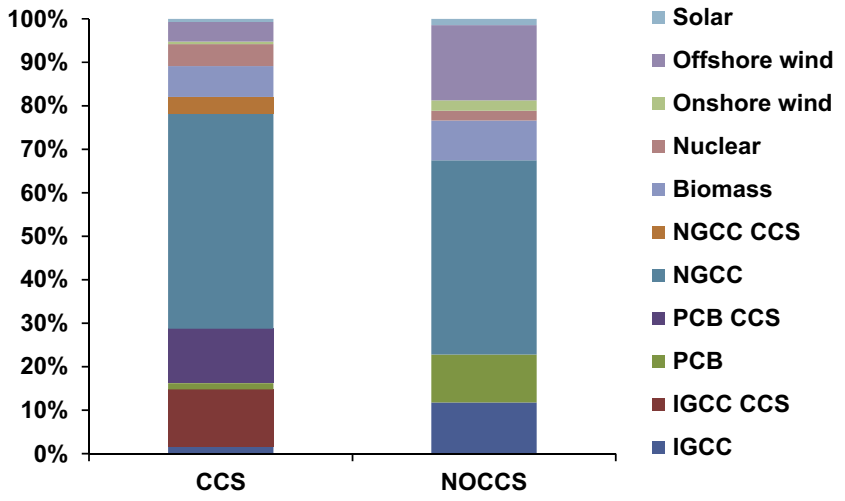

Fig. 3. Technology shares in total monetary power production in the Netherlands in 2030. (We divide the production of wind into on and offshore wind power by using the proportions of wind power potentials estimated for the Netherlands in 2050 [4].)

of the output in the CCS scenario. The major differences are in wind power and fossil fueled thermal power. Wind makes $20 \%$ of the output in the NOCCS scenario but $5 \%$ in the CCS-inclusive portfolio. Instead, this scenario generates over $80 \%$ of the output with thermal fossil fuel plants, where in the NOCCS these account for a little over $65 \%$ of output in 2030. Notable, nuclear power takes $5 \%$ in the CCS scenario, but is only producing $2 \%$ of the output in the NOCCS scenario. Biomass, in contrast, accounts for $9 \%$ of the monetary value of power output in the NOCCS scenario but only $7 \%$ in the CCS scenario.

The scenarios imply that emissions from power production in 2030 differ between the scenarios. ${ }^{16}$ Emissions are higher in 2030 in the NOCCS scenario. Direct gross value added from power production is also higher in 2030 in this scenario. The imposed distribution over the technologies making up the total power production portfolio drives our results on differential impacts upstream. We discuss these below.

\subsection{GVA in the Netherlands}

Although the total gross output in the Netherlands is similar in both scenarios, the differences in GVA between the two scenarios are still noteworthy. There is around EUR ${ }^{17} 800,000,000$ less GVA in the CCS scenario. Compared to total GVA in the Netherlands in 2007 this is small $(0.15 \%)$, but the difference equals $20 \%$ of the total GVA from power production in 2007. The main cause of the lower GVA in the CCS scenario is the lower direct GVA from power production of about EUR 1,200,000,000 (Table 5), which is $28 \%$ of the GVA from power production in 2007. Power production in the NOCCS scenario is more GVA intensive as a result of the higher $\mathrm{CO}_{2}$ emissions from coal power without capture in the NOCCS power mix. The reason for this is that $\mathrm{CO}_{2}$ emissions are valued by the carbon price and treated as a tax in the IO-table. Taxes are part of GVA. As a consequence higher emissions lead to higher expenses on $\mathrm{CO}_{2}$ emissions increasing GVA and making the NOCCS scenario more GVA intensive. If the expenditure on $\mathrm{CO}_{2}$ emissions was not treated as a tax in the accounting framework of the IO-table, GVA in the NOCCS scenario was still higher than in the CCS scenario by about EUR 586,000,000. ${ }^{18}$

\footnotetext{
${ }^{16}$ Note that scenarios were calibrated to yield the same emission levels only by 2050. Assuming power production to be around $140 \mathrm{TWh}$ in 2030 [78] in both scenarios and using the carbon contents and efficiencies given in Table 2, emissions are around $11 \mathrm{MtCO}_{2}$ higher for the NOCCS scenario.

17 All results have been converted from EUR $_{2007}$ to EUR $_{2010}$ using the CPI for OECDEurope of $0.93(2010=1)$ from [79].

18 Note: this does not imply that the difference in carbon emission expenses is EUR $200,000,000$. The difference in taxes is around EUR 1,000,000,000. The reason why excluding the tax share from the LCOE and the IO-table, still results in higher GVA for the NOCCS scenario, is that we keep output constant and therefore other differences intensify.
}

GVA in upstream sectors is somewhat higher in the CCS scenario. In total the difference adds up to about EUR 335,000,000 but GVA of some sectors is affected disproportionally. Fig. 4 shows the aggregated product results, while in Table 5 results of the few most affected products or services are listed together with the differential between the two scenarios and the difference in percent of GVA from producing this product in 2007.

From the table it is clear that the most important reason for higher upstream GVA in the CCS scenario comes from more GVA in natural gas extraction and distribution services. This is directly linked to the higher share of natural gas power in this scenario. Together these sectors have higher GVA by more than EUR $700,000,000$ (Table 5). This is 5\% more GVA in the CCS scenario for natural gas extraction and distribution services compared to the NOCCS scenario. There is also considerably less demand for construction in the CCS scenario because of the lower share of construction intensive renewables. The latter have higher capital cost than thermal power plants and by our inclusion of capital expenditures they thus imply more expenditure on construction.

The last column of Table 5 shows that lower GVA from production of wood products results mainly from the lower use of biomass power in the 2030 scenario including CCS. A considerable share of the lower GVA from wood products, however, is also an indirect result of the lower construction activity in the CCS scenario. This might seem surprising but by the nature of IO-Models the input vectors contain information for average input requirements. The average input of wood products to construction services might be higher than the amount of wood products used for the construction of renewable power technologies.

\subsection{Gross employment in the Netherlands}

As might be expected, the gross employment differences between the two scenarios on the macro-level of the Netherlands are even more moderate compared to the total 2007 workforce than the GVA results. The difference amounts to about 6,000 jobs (in FTE) less in the CCS scenario, which is a negligible $0.07 \%$ of the 2007 workforce in the Netherlands. However, compared to direct employment in power production alone (excluding transmission and distribution) this is still considerable. Direct employment in power production roughly amounts to 13,300 jobs in the IO-table of 2007 , which makes for only $0.2 \%$ of the total employment in the Netherlands in 2007. The difference in total employment between the scenarios is therefore $45 \%$ of this number. As many of these jobs are, however, lost and gained in upstream sectors, it is not appropriate to scale this impact by power production labor only.

Unlike upstream GVA, upstream employment is in total still lower in the CCS scenario (around 5700 FTE). One major reason is the lower demand for construction services. As mentioned above construction services are demanded more in the NOCCS scenario because the larger share of non-biomass renewables (in particular wind power). These have a higher share of capital cost and the share of construction services in capital cost of these technologies is higher as well. Construction services are employment intensive and therefore the differential in employment between the scenarios is about 3,400 jobs (Fig. 5). As employment intensity in natural gas extraction is much lower than in construction the extra natural gas demand in the CCS scenario does not result in nearly enough extra employment to outweigh the higher employment from construction in the NOCCS scenario. As can be seen in Fig. 5, the extra employment from mining (which includes natural gas extraction) in the CCS scenario is small compared to the extra employment from construction in the NOCCS scenario. The opposite is true for gross value added. Here, the differential in GVA from mining is 
Table 5

Products/services in NL with significantly lower or higher GVA or employment in the CCS scenario.

\begin{tabular}{|c|c|c|c|c|c|}
\hline & $\begin{array}{l}\text { GVA CCS-NOCCS } \\
\text { (million EUR) }\end{array}$ & $\begin{array}{l}\text { CCS-NOCCS as \% of } \\
2007 \text { GVA in this sector }\end{array}$ & $\begin{array}{l}\text { FTE } \\
\text { CCS- } \\
\text { NOCCS }\end{array}$ & $\begin{array}{l}\text { FTE CCS-NOCCS as \% of } \\
\text { employment in this sector in } \\
2007\end{array}$ & $\begin{array}{l}\text { Most important demanding } \\
\text { sector }\end{array}$ \\
\hline Electricity production & $-1,153$ & $-28.4 \%$ & -291 & $-2.2 \%$ & $\begin{array}{l}\text { Direct impact of power } \\
\text { production }\end{array}$ \\
\hline Wood and products of wood and cork & -17 & $-1.3 \%$ & -259 & $-1.3 \%$ & Biomass power, construction \\
\hline Construction & -237 & $-0.7 \%$ & $-3,432$ & $-0.7 \%$ & $\begin{array}{l}\text { All power options, main } \\
\text { difference is made by } \\
\text { renewables }\end{array}$ \\
\hline $\begin{array}{l}\text { Natural gas and services related to natural } \\
\text { gas extraction, excluding surveying }\end{array}$ & 647 & $4.3 \%$ & 210 & $4.3 \%$ & Natural gas power \\
\hline $\begin{array}{l}\text { Distribution services of gaseous fuels } \\
\text { through mains }\end{array}$ & 74 & $3.4 \%$ & 291 & $3.4 \%$ & Natural gas power \\
\hline Total difference CCS-NOCCS & -818 & $-0.15 \%$ & $-6,024$ & $-0.07 \%$ & \\
\hline
\end{tabular}

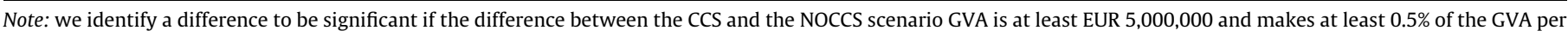
product in the 2007 table. For employment the threshold is 100 FTE and $0.5 \%$.

Positive numbers mean GVA or employment is larger if the CCS scenario.

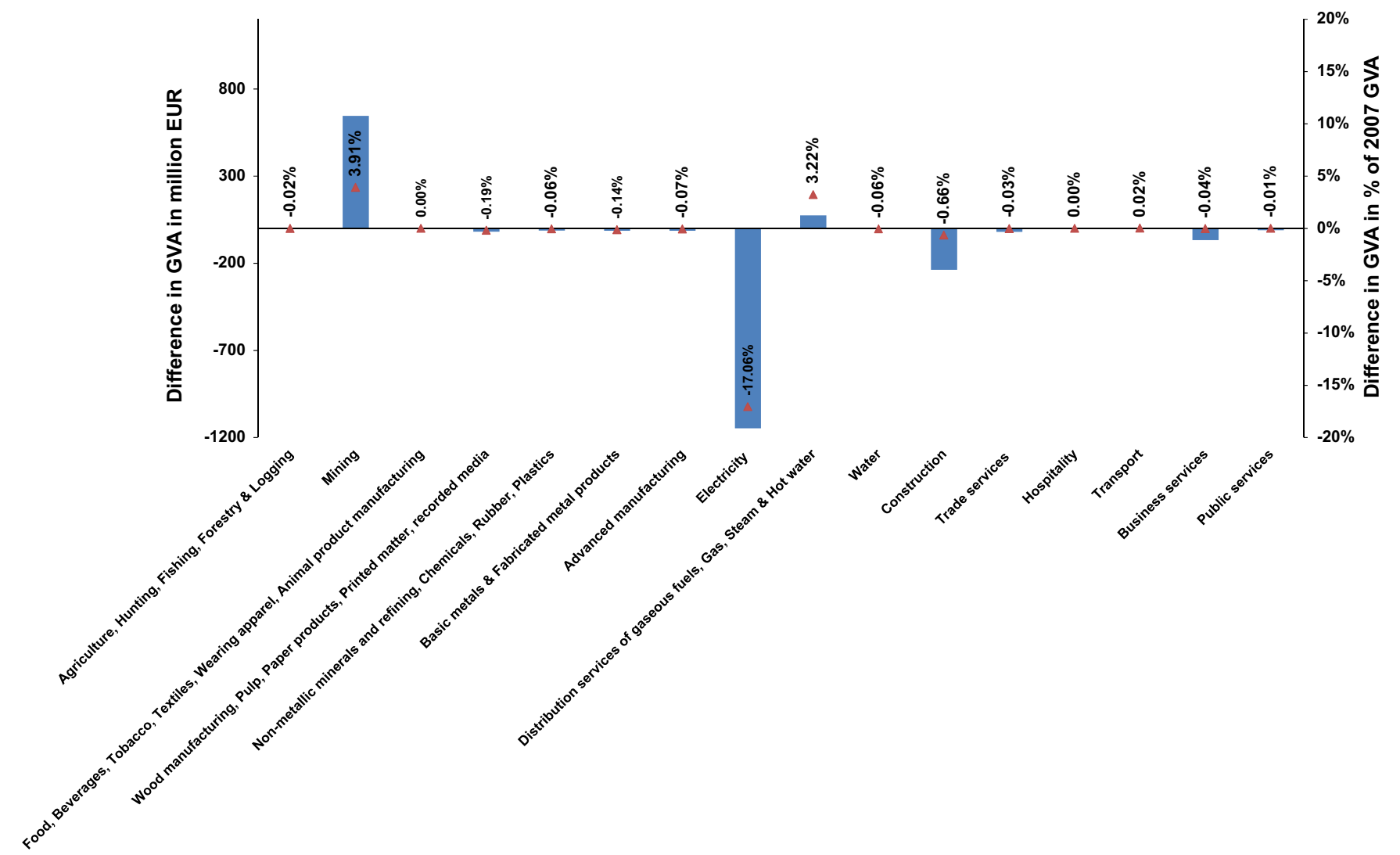

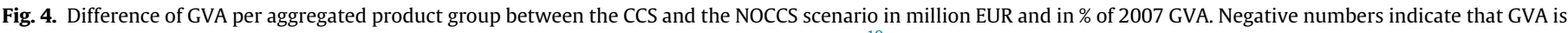
higher in the NOCCS scenario, while positive numbers indicate more GVA in the CCS scenario. ${ }^{19}$

about three times the amount of extra GVA from construction in the NOCCS scenario.

Also, there are about 290 full-time equivalent (FTE) less jobs from power production in the CCS scenario. This makes only around $2 \%$ of the employment in power production 2007. This is low compared to the GVA difference in the power sector. The reason is that employment intensity of power production does not differ as much between the scenarios as GVA intensity. Power production from coal and natural gas is more employment inten-

\footnotetext{
19 Note, the product groups in this graph are aggregated. Therefore, the numbers differ from the numbers of individual products in Table 5. For details about product aggregation see supplementary material.
}

sive in the CCS scenario because CCS options need more labor than the non-capture thermal plants. In the NOCCS scenario this is compensated because renewable power, in particular wind power, is more employment intensive than fossil fuel based power production.

\subsection{Trade impacts}

Overall the CCS-inclusive strategy is more import dependent. In total, imports to the Netherlands are higher by about EUR $780,000,000$ in the CCS-inclusive scenario. To put that difference into context, this is about $0.4 \%$ of the total intermediate imports in the 2007 IO-table database. The extra imports in the CCS 


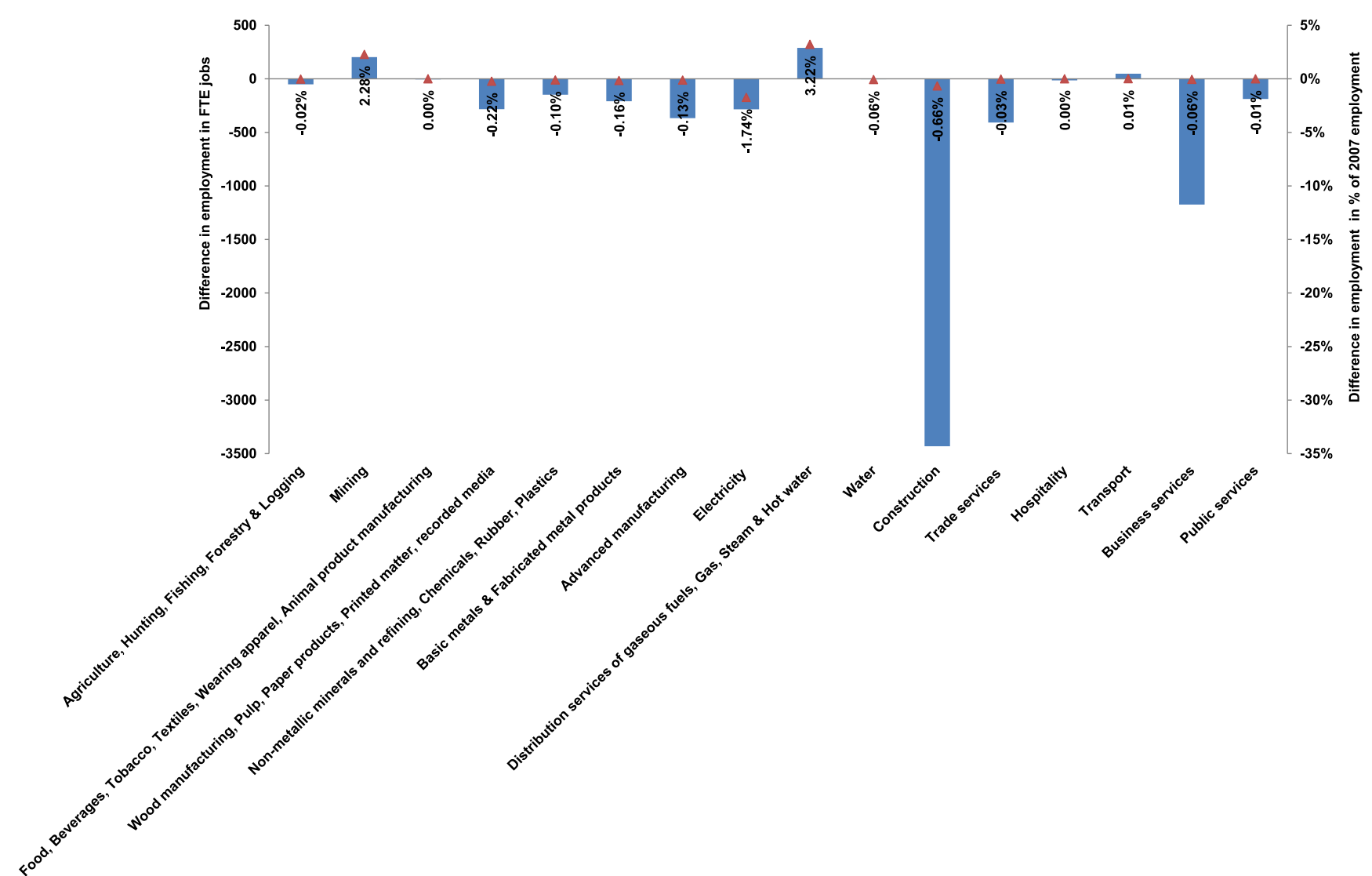

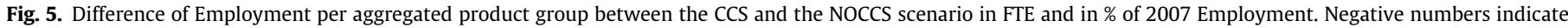
that Employment is higher in the NOCCS scenario, while positive numbers indicate more Employment in the CCS scenario. ${ }^{20}$

scenario mostly come from outside the European Union and are largely due to higher imports of coal, natural gas, and nuclear fuels (Table 6). Only wood imports are notably lower in the CCS scenario as less biomass electricity is foreseen in it in 2030.

Overall this makes the CCS scenario more import dependent and decreases energy security. However, coal imports are typically not associated with concerns of energy security. Coal can be imported from a variety of countries, many much more stable and reliable than the sources of natural gas and oil.

The higher import dependency in the CCS scenario is slightly moderated by the lower imports from EU regions. Although this alleviates the difference in imports by $10 \%$ of its value from the rest of the world, this is less important with respect to energy security as intra EU trade can be considered less risky than from regions outside the trade union. Intra-EU imports are lower in the CCS scenario mainly due to the lower imports of bio-energy wood (Table 7), most of which comes from Germany, Belgium, Sweden and Finland as suggested by the trade links of the 2007 IO-table database. This lower biomass intensity is somewhat offset by higher nuclear fuel imports from the European Union (mostly from France). It should be noted, however, that the raw uranium used in France is sourced outside of the European Union [60,61].

\subsection{Overall observations}

From our counterfactual implementation of the CCS and NOCCS scenarios in an IO-Model for the Netherlands we learn that upstream impacts differ significantly between mitigation

\footnotetext{
$\overline{20}$ Note, the product groups in this graph are aggregated. Therefore, the numbers differ from the numbers of individual products in Table 5. For details about product aggregation see supplementary material.
}

strategies that in- and exclude CCS. Including CCS benefits upstream sectors of in particular the fossil fuel based power production like gas and coal mining. As $\mathrm{CO}_{2}$ emissions are higher in total in the NOCCS scenario in 2030, this scenario imposes more taxes on the remaining carbon emitting power sector that retains a share of $65 \%$ in total production in 2030 . Consequently power sector GVA will be higher, although this can of course not be interpreted as a positive outcome. Of the higher levels of activity in the renewable sector the upstream effects benefit in particular construction and wood products, given that more co-firing of biomass is required in the NOCCS scenario to achieve the emission reductions. Through these main channels the impacts on employment and trade also follow. Our simulations have not only uncovered the signs but also give an order of magnitude for the effects. In comparison with the total economy, impacts are shown to be very small, but for individual sectors the impacts can be substantial. We discuss the implications and limitations of our results below. First the next section will present our sensitivity analysis. ${ }^{21}$

\section{Sensitivity analysis}

In this section we test a number of key uncertainties. In particular we will investigate the impact of (1) changing bio-energy import shares, (2) changing natural gas import shares and (3) considering alternative portfolio mixes for the two scenarios. Table 8 gives an overview of all macro-level results.

From the table we see that our results are not very sensitive to the different assumptions made and changes are all in the expected

\footnotetext{
21 Note, that while the emission reduction is not exactly the same in these scenarios in 2030 , the NOCCS case does use more renewables to compensate for the foregone contribution of CCS
} 
Table 6

Significant import differences between the CCS and NOCCS scenario for imports from RoW.

\begin{tabular}{|c|c|c|c|c|c|}
\hline Imported product & $\begin{array}{l}\text { Intermediate imports } \\
\text { in CCS scenario } \\
\text { (million EUR) }\end{array}$ & $\begin{array}{l}\text { Intermediate imports in } \\
\text { NOCCS scenario (million } \\
\text { EUR) }\end{array}$ & $\begin{array}{l}\text { Difference between CCS } \\
\text { NOCCS scenario (million } \\
\text { EUR) }\end{array}$ & $\begin{array}{l}\text { Difference relative to } \\
\text { intermediate imports } \\
\text { in } 2007\end{array}$ & $\begin{array}{l}\text { Import difference appears } \\
\text { mainly due to imports for the } \\
\text { production of: }\end{array}$ \\
\hline Bituminous coal & 1,929 & 1,208 & 720 & $211 \%$ & Coal power production \\
\hline $\begin{array}{l}\text { Natural gas and services } \\
\text { related to natural gas } \\
\text { extraction }\end{array}$ & 1,034 & 915 & 118 & $10 \%$ & Natural gas power production \\
\hline Wood products & 468 & 496 & -29 & $-7 \%$ & Biomass power production \\
\hline Nuclear fuel & 58 & 36 & 22 & $132 \%$ & Nuclear power production \\
\hline $\begin{array}{l}\text { Transportation services } \\
\text { via pipelines }\end{array}$ & 297 & 287 & 10 & $3 \%$ & $\begin{array}{l}\text { Natural gas extraction \& related } \\
\text { services }\end{array}$ \\
\hline Total imports from RoW & 97,047 & 96,185 & 861 & $0.9 \%$ & - \\
\hline
\end{tabular}

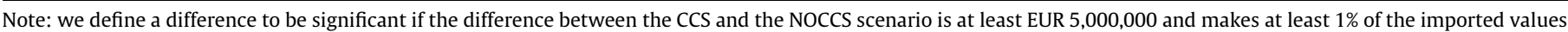
per product in the 2007 table.

Positive numbers mean that more is imported of this product if the CCS scenario is in place and vice versa for negative values.

Table 7

Significant import differences between the CCS and NOCCS scenario for imports from remaining Europe.

\begin{tabular}{|c|c|c|c|c|c|}
\hline Product & $\begin{array}{l}\text { Intermediate imports in } \\
\text { CCS scenario (million } \\
\text { EUR) }\end{array}$ & $\begin{array}{l}\text { Intermediate imports in } \\
\text { NOCCS scenario (million } \\
\text { EUR) }\end{array}$ & $\begin{array}{l}\text { Difference between CCS } \\
\text { NOCCS scenario (million } \\
\text { EUR) }\end{array}$ & $\begin{array}{l}\text { Difference relative to } \\
\text { intermediate imports in } \\
2007\end{array}$ & $\begin{array}{l}\text { Import difference appears mainly } \\
\text { due to imports for the production } \\
\text { of: }\end{array}$ \\
\hline $\begin{array}{l}\text { Wood and } \\
\text { products of } \\
\text { wood and cork }\end{array}$ & 1,776 & 1,884 & -108 & $-7 \%$ & Biomass power, construction \\
\hline Nuclear fuel & 70 & 43 & 27 & $132 \%$ & Nuclear power \\
\hline $\begin{array}{l}\text { Total intermediate } \\
\text { imports from } \\
\text { Europe }\end{array}$ & 82,541 & 82,627 & -86 & $-0.1 \%$ & - \\
\hline
\end{tabular}

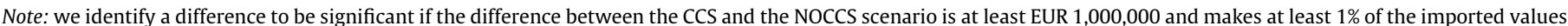
per product in the 2007 table.

Positive numbers mean that more is imported of this product if the CCS scenario is in place and vice versa for negative values.

direction. None of the impacts change the sign of the difference between the CCS and the NOCCS scenario in total imports, GVA or employment compared to the reference scenario and despite strong changes to the import intensities and elimination of nuclear from both portfolios we find the total effects rather stable and robust. Below we justify our assumptions in the sensitivity analysis and present the outcomes in more detail.

\subsection{Biomass imports}

In our baseline simulation the import shares for wood products in the IO-table are $80 \%$ of which $63 \%$ is imported from EU regions and $17 \%$ are from outside the EU. Goh \& Junginger [53] present data on the imports of biomass co-fired in power plants in the Netherlands between 2010 and 2013. Between approximately 17-27\% (roughly 2.5-9 PJ) is from domestic sources. EU imports vary between $12 \%$ and $18 \%$ (roughly $2.4-4.8 \mathrm{PJ}$ ) and non-EU imports vary between $61 \%$ and $66 \%$. At the same time, it can be observed that only wood pellets are imported for co-firing, while in 2013 domestic supply of bio-energy feedstocks for co-firing is also limited to wood pellets [53]. Therefore, we limit the analysis to woody biomass. In Elbersen et al. [54], the total potential for woody biomass domestically produced in 2030 adds up to around $50 \mathrm{PJ}$. However, it is unlikely that the full potential is available for co-firing as there are competing uses and some sources could be unsuitable for co-firing. Therefore, we assume a limit on domestic potential of 20 $\mathrm{PJ}$. The feedstock demand for co-firing in the two scenarios in 2030 would be around $67-87$ PJ. Thus, a maximum of $20-30 \%$ of the bioenergy used can come from domestic sources in these scenarios. We therefore, test in a sensitivity analysis how results change if

- we decrease domestic supply of biomass for power to $10 \%$ (case (b)),
- we restrict EU imports of biomass to $10 \%$ (case (c)),

- we decrease domestic supply of biomass for power to $10 \%$ and restrict EU imports of biomass to $10 \%$ (case (d)).

Predictably, under all three alternatives (cases (b)-(d)) the GVA remains noticeably lower in the Netherlands under the CCS scenario (Table 8). Similarly, the gap in employment between the CCS and the NOCCS scenario hardly changes if the production of bio-energy fuel for power in the Netherlands and/or imports from remaining Europe decreases.

The difference in import dependency between the two scenario decreases for imports from outside of the European Union (see Table 8). The reason is the larger use of biomass in the NOCCS portfolio. Therefore, increasing imports for bio-energy enlarges the import dependency for the NOCCS power production portfolio somewhat more than the CCS scenario. Departing from a situation where import dependency is stronger in the CCS scenario, the latter can be somewhat off-set. However, the overall result of higher import dependency in the CCS scenario proves not to be too sensitive to the exact level of the import intensity for biomass. The effect is not strong enough to reverse our conclusion and the CCS scenario remains the more import intensive.

\subsection{Natural gas imports}

The ministry of economic affairs of the Netherlands published a 2030 forecast of natural gas production of $16.2 \mathrm{bcm}$ while they forecast consumption to be about $31.1 \mathrm{bcm}$ [62]. Thus, they expect about $48 \%$ of natural gas to be imported. Another forecast suggests consumption of natural gas in the Netherlands in 2030 to be around $43 \mathrm{bcm}$ [63]. Assuming the same level of production, imports would then be around $63 \%$. In the sensitivity analysis we therefore changed import shares for natural gas used in power 
Table 8

Overview of macro-level results for base case and sensitivity analysis.

\begin{tabular}{|c|c|c|c|c|c|c|c|c|c|c|c|}
\hline & \multicolumn{3}{|c|}{ Intermediate imports (million EUR) } & \multirow{2}{*}{$\begin{array}{l}\text { GVA } \\
\text { (million EUR) } \\
\text { NL }\end{array}$} & \multirow{2}{*}{$\begin{array}{l}\text { Employment } \\
\text { (1000 FTE jobs) } \\
\text { NL }\end{array}$} & & \multicolumn{3}{|c|}{ Intermediate imports (million EUR) } & \multirow{2}{*}{$\begin{array}{l}\text { GVA } \\
\text { (million EUR) } \\
\text { NL }\end{array}$} & \multirow{2}{*}{$\begin{array}{l}\text { Employment } \\
\text { (1000 FTE jobs) } \\
\text { NL }\end{array}$} \\
\hline & $\mathrm{EU}$ & RoW & $\begin{array}{l}\text { Total intermediate } \\
\text { imports }\end{array}$ & & & & $\mathrm{EU}$ & RoW & $\begin{array}{l}\text { Total intermediate } \\
\text { imports }\end{array}$ & & \\
\hline (a) Base case & & & & & & $\begin{array}{l}\text { (e) Natural gc } \\
40 \%\end{array}$ & mports & & & & \\
\hline CCS & 82,541 & 97,047 & 179,588 & 545,948 & 8,576 & CCS & 82,459 & 98,781 & 181,240 & 544,405 & 8,573 \\
\hline NOCCS & 82,627 & 96,185 & 178,812 & 546,766 & 8,582 & NOCCS & 82,558 & 97,627 & 180,185 & 545,483 & 8,579 \\
\hline CCS-NOCCS & -86 & 861 & 776 & -818 & -6 & CCS-NOCCS & -100 & 1,154 & 1,055 & $-1,078$ & -7 \\
\hline$\%$ of ref & $-0.10 \%$ & $0.89 \%$ & $0.43 \%$ & $-0.15 \%$ & $-0.07 \%$ & $\%$ of ref & $-0.12 \%$ & $1.20 \%$ & $0.6 \%$ & $-0.20 \%$ & $-0.08 \%$ \\
\hline $\begin{array}{l}\text { (b) Biomass } \\
\text { NL 10\%/EU 65\%/RoW 25\% }\end{array}$ & & & & & & $\begin{array}{l}\text { (f) Natural ga } \\
60 \%\end{array}$ & mports & & & & \\
\hline CCS & 82,540 & 97,086 & 179,626 & 545,913 & 8,575 & CCS & 82,404 & 99,952 & 182,355 & 543,362 & 8,570 \\
\hline NOCCS & 82,625 & 96,236 & 178,861 & 546,720 & 8,581 & NOCCS & 82,513 & 98,599 & 181,112 & 544,617 & 8,577 \\
\hline CCS-NOCCS & -85 & 850 & 765 & -807 & -6 & CCS-NOCCS & -109 & 1,352 & 1,243 & $-1,255$ & -7 \\
\hline$\%$ of ref & $-0.1 \%$ & $0.9 \%$ & $0.425 \%$ & $-0.15 \%$ & $-0.07 \%$ & $\%$ of ref & $-0.13 \%$ & $1.40 \%$ & $0.7 \%$ & $-0.23 \%$ & $-0.08 \%$ \\
\hline $\begin{array}{l}\text { (c) Biomass } \\
\text { NL } 20 \% / \text { EU 10\%/RoW 70\% }\end{array}$ & & & & & & (g) No-nuclea & nore renew & & & & \\
\hline CCS & 82,243 & 97,343 & 179,586 & 545,948 & 8,576 & CCS & 82,523 & 96,979 & 179,502 & 546,020 & 8,579 \\
\hline NOCCS & 82,243 & 96,567 & 178,810 & 546,765 & 8,582 & NOCCS & 82,617 & 96,162 & 178,780 & 546,792 & 8,583 \\
\hline CCS-NOCCS & 0 & 776 & 776 & -817 & -6 & CCS-NOCCS & -94 & 817 & 722 & -771 & -4 \\
\hline$\%$ of ref & $0 \%$ & $0.81 \%$ & $0.43 \%$ & $-0.15 \%$ & $-0.07 \%$ & $\%$ of ref & $-0.11 \%$ & $0.85 \%$ & $0.40 \%$ & $-0.14 \%$ & $-0.05 \%$ \\
\hline $\begin{array}{l}\text { (d) Biomass } \\
\text { NL } 10 \% / \text { EU10\%/RoW 80\% }\end{array}$ & & & & & & (h) Shares of & & & & & \\
\hline CCS & 82,233 & 97,392 & 179,625 & 545,911 & 8,575 & CCS & 82,262 & 98,299 & 180,561 & 545,013 & 8,578 \\
\hline NOCCS & 82,230 & 96,630 & 178,860 & 546,719 & 8,581 & NOCCS & 82,660 & 95,226 & 177,886 & 547,629 & 8,608 \\
\hline CCS-NOCCS & 2 & 762 & 765 & -807 & -6 & CCS-NOCCS & -398 & 3,073 & 2,675 & $-2,616$ & -30 \\
\hline$\%$ of ref & $0 \%$ & $0.79 \%$ & $0.43 \%$ & $-0.15 \%$ & $-0.07 \%$ & $\%$ of ref & $-0.48 \%$ & $3.19 \%$ & $1.49 \%$ & $-0.48 \%$ & $-0.35 \%$ \\
\hline
\end{tabular}


production to $40 \%$ (case (e)) and $60 \%$ (case (f)), respectively. Since Europe will be net importer of natural gas as a whole, we assume in the scenarios that all natural gas imports come from outside EU regions.

Increasing natural gas import shares (for power production) decreases GVA in the Netherlands in both scenarios, but more so in the CCS scenario because natural gas is used more in this scenario (see Table 8). This results in a larger gap in GVA between the scenarios. It roughly amounts to between EUR 1,000,000,000 (case (e)) and EUR 1,300,000,000 (case (f)) more GVA in the NOCCS scenario for natural gas import shares of $40 \%$ (case (e)) and $60 \%$ (case (f)), respectively. The main reason is the lower domestic natural gas production, which decreases more in the CCS scenario, such that the additional GVA (in natrual gas production) in the CCS scenario over the NOCCS scenario decreases by one third in case (e) and by one half in case (f).

As shown in Table 8, the decrease of employment in both scenarios is less pronounced than GVA because natural gas production has low employment intensity. The difference in total employment between the scenarios increases to 6,600 (in case (e)) and 7,000 (in case (f)) more jobs in the NOCCS scenario for $40 \%$ and $60 \%$ import shares of natural gas, respectively.

Obviously, import dependency increases more strongly in the more natural gas intensive CCS scenario. With an import share for natural gas of $60 \%$ in case (f), total imports are more than EUR 1,000,000,000 higher compared to the NOCCS strategy. This amounts to about $0.7 \%$ of the total intermediate imports to the Netherlands in 2007. Overall, higher import shares of natural gas for power production make the disadvantage of the CCS scenario compared to the NOCCS scenario larger with respect to all three indicators. The effects are small on employment but somewhat stronger on GVA and import dependency.

\subsection{Alternative assumptions about portfolio shares}

We also explored different assumptions on the portfolio shares. First, given the controversy on the role of nuclear power, we look at the exclusion of nuclear power from both scenarios (case (g)). Second, we look at the portfolios as proposed by Koopmans et al. [7] for 2050 (case (h)).

\subsubsection{More renewable - No nuclear power}

In this analysis we change the physical power shares of the base scenario shown in Table 1 . The aim of this sensitivity test is twofold. First, because renewable share of $13 \%$ in the CCS scenario in 2030 is low compared to the official targets of $16 \%$ renewable energy in 2023 [64], we should consider the possibility that politically the CCS scenario is not ambitious enough. Therefore, higher renewable shares in both scenarios in 2030 may well become a reality. Second, we want to investigate the scenarios when nuclear power is not an option, as many do not consider nuclear power to be renewable or sustainable, even if it is a low-carbon technology. Thus, we allocated the nuclear power shares in both scenarios to the renewable options. The allocation is done proportional to the share in power production of each renewable option (onshore and offshore wind, solar PV). As a result total renewable power production in the CCS scenario increases to $21 \%$ in the CCS scenario and $37 \%$ in the NOCCS scenario (including bio-energy).

The result of the changes of case $(\mathrm{g})$ in both - the CCS-inclusive and the CCS-exclusive scenario - is that the differentials between the indicators decrease for total imports, employment and GVA (see Table 8). Employment increases in both scenarios but more in the CCS-inclusive scenario largely because the increase in employment intensive offshore wind is stronger than in the CCSexclusive scenario and since import dependency decreases more in the CCS scenario leading to a larger increase in domestic production positively affecting employment and GVA. Similarly, GVA increases more in the CCS-inclusive scenario than in the CCSexclusive scenario, which reduces the differential somewhat (see Table 8). These effects are the result of nuclear taking a larger share in the original CCS portfolio (the relative increase in renewable power production is then higher in the CCS-inclusive scenario), employment intensity being higher for wind power technologies and a stronger decrease in imports in the CCS scenario. Quantitatively, however, the impact is still mild.

\subsubsection{Implementing the portfolio shares for 2050}

Case (h) looks at the results when using scenarios for the year 2050. Koopmans et al. [7] developed their scenarios for power production shares until 2050. The shares they propose for 2050 were already shown in Table 1 in Section 2.2. As a robustness test we also implemented that portfolio to see if the comparison of the CCS and the NOCCS scenario would change. ${ }^{22}$

Using the 2050 shares makes the differences in GVA, employment and import dependency between the two scenarios significantly more pronounced (see Table 8). The difference in GVA between the scenarios of case $(h)$ becomes about three times as large as the difference between the scenarios of the base case. GVA decreases in the CCS scenario going from the base case (2030) portfolio to the portfolio in case (h) (2050), to a large extent due to large shares of natural gas power being replaced by coal power with CCS. The decline must mainly result from the fact that natural gas is to a larger share produced domestically while coal is imported. In contrast, GVA in the NOCCS scenario increases, because of the higher renewable share. Two reasons are: First, direct GVA is higher than in the base case, because offshore wind and solar PV are more GVA intensive than natural gas fired power production. Second, much of the coal power used in 2030 is replaced by renewable technologies, which have higher domestic upstream demands (in fact, over $80 \%$ of intermediate inputs to renewable power is domestically produced compared to $20 \%$ for coal fired power). This mostly can be observed in the higher GVA from construction and business services in the NOCCS scenario in 2050. Moreover, the difference in natural gas use for power between the two scenarios decreases from the base case (2030) to case (h) (2050). Thus the large difference in upstream impacts that was largely driven by the natural gas production in the 2030 comparison diminishes in the 2050 comparison (case (h)). Overall this also results in lower upstream GVA in the CCS scenario compared to the NOCCS scenario, which was the opposite in the base case comparison for 2030.

Consistently, while employment was higher by about 6,000 jobs in the NOCCS scenario in 2030 (base case), this differential now increases to about 30,000 more jobs for NOCCS in 2050 (case (h)). The largest differential can be observed in the construction sector. Inputs of this service to renewable power production are much higher than for fossil fuel based power production. Moreover, most of this production takes place domestically, unlike the case for imported coal. Additionally, the labor intensity of construction is above average. Therefore, the sharp increase in renewable power from 2030 to 2050 (base case to case (h)) in the NOCCS scenario strongly widens the gap in employment between the two power production strategies. It should be noted here, however, that this is a result of our distribution of investment expenditures to intermediary deliveries. In part this is a fair comparison, because a lot of the investment is replacement of depreciated production assets, but part is also the creation of the production facilities. It is not exactly clear when the related construction activities will

\footnotetext{
$\overline{22}$ Note, that we only adjust the portfolio shares to 2050, but not carbon, or fuel.
} 
be demanded. We implicitly assumed they are spread in time equally.

Finally, import dependency significantly increases in the CCS scenario and decreases in the NOCCS scenario (see Table 8). Overall the additional imports in the CCS scenario under the 2050 power production mix of case $(\mathrm{h})$ are as large as $1.5 \%$ of all intermediate imports to the Netherlands in 2007. This is mostly because more coal (than under the 2030 base case portfolio) is imported in the CCS scenario, whereas much less coal is imported in the NOCCS scenario. As a consequence, the differential in imports from outside the EU between the CCS and the NOCCS scenario increases to about EUR 3,000,000,000. Thus, with a more extreme difference between the portfolios, predictably the differences in results also become more pronounced. The 2050 portfolio (case (h)) makes the comparative attractiveness of the NOCCS scenario over the CCS power mix stronger. However, as mentioned above imports of coal are less of a concern for import dependency than other fossil fuels.

\section{Discussion}

The main result of our analysis is that the CCS-inclusive strategy is less favorable for the power sector in the Netherlands in terms of GVA, employment and energy security when we compare it to a portfolio that is dominated by renewables. ${ }^{23}$ This result is qualitatively robust on the macro-level with respect to changes in bioenergy and natural gas import shares, as well as for portfolios where nuclear power is excluded and strengthened when we consider portfolios that would be realistic in 2050. We made this comparison for the Netherlands by implementing two alternative power production portfolios in a static Input-Output framework and results should be interpreted with caution. Our results are not to be interpreted as predictions. Instead we present the counterfactual where we implement the two scenarios of interest in the Dutch 2007 economy. Still there are several implications for policy we will discuss first. Then, we discuss a number of important issues that are relevant to interpret and qualify our results. These are limitations in the study scope, the scenario availability, the data availability and the method.

\subsection{Policy implications and relevance}

Groenenberg and de Conink [65] in a multicriteria analysis of CCS policy instruments already concluded that different European member states might have different views on energy transition strategies and more specifically on CCS promotion policies depending on the structure of their energy system and economy. Their solution, however, instead of trying to identify and accommodate such fundamental differences, was to lift CCS policy to the EU level to ensure stable support for CCS. In 2008 their analysis was that carbon pricing in the ETS could serve as a strong incentive for CCS but additional policy interventions by the EU would be required in a weak ETS scenario. In De Conink et al. [66] a large group of researchers concluded from interviews and stakeholder consultations that there were no scientific, technical or economic barriers to deployment of CCS in Europe. The main policy challenges were perceived in creating social acceptance (e.g. Shackley et al. [67], Johnsson et al. [68], Terwel et al. [69])

With the global financial crisis and collapse of the European carbon prices, however, the weak ETS scenario has now materialized. In policy circles the debate on the economics of CCS has now gained new momentum. The technology is ready for large-scale demonstration and there is an urgent need to cut GHG emissions. But CCS suffers from high up front capital costs and the business case still relies strongly on (financial) government support. And as governments struggle to deal with the economic recession, the private sector seems to lose interest. Commercial parties all over Europe abandon or mothball their projects. Consequently, progress in the diffusion of CCS has all but grinded to a halt. The European Commission's ambition to have 12 commercial scale CCS demonstration projects up and running by 2015 has stalled because of lacking private funding and last June the Guardian reported the UK mothballed its 1 billion GBP research program on CCS reevaluating its priorities after the Brexit vote. All this shows that the deployment of CCS is vulnerable and highly dependent on policy. Its future success will thus depend on whether a stable coalition can be built to support CCS in the long run.

In 2012 the International Energy Agency (IEA) [70], stressed the importance of explicitly investigating "political acceptability". The IEA [70] states: "Policies may be more or less politically acceptable depending on familiarity and confidence in the outcome, trust in institutions, impact on special interest groups or the distribution of costs between firms, consumers and tax payers." [70 p. 20, emphasis added]. In their analysis of policy options and instruments they then focus on overcoming the resistance to Carbon Capture and Storage under the assumption that such a policy is both desirable and decided upon and treats the business sector and consumers as homogeneous groups.

We feel, however, that for a proper mapping of all relevant interests one should also consider the winners of a strategy excluding CCS (i.e. producers of solar and wind power and sectors supplying them). They could prove a much stronger lobby against CCS than the sectors a CCS policy needs to compensate for higher costs (i.e. gas and coal fired power producers). Our results show that macroeconomic impacts of in- or excluding CCS from the mitigation strategy differ substantially between firms and workers across sectors. Some sectors gain, some sectors lose. The identification of potential losers and an assessment of the order of magnitude of such losses is evidently important for developing an effective GHG-abatement policy with or without CCS. In our analyses we show that excluding CCS would benefit the upstream sectors of renewable energy production, notably construction and biomass production (given that more biomass is used in the CCS-exclusive scenario). ${ }^{24}$ As such sectors are relatively labor intensive, in terms of jobs and employment, the gains could outweigh the costs and excluding CCS could thus gain the support of labor unions and the broader population, especially when government budgets are tight. The losses when CCS is excluded are concentrated in the relatively low labor but high value added sectors in natural gas mining. As for the Netherlands natural gas production is significant domestically, the biggest resistance to excluding CCS and biggest support for promoting it could be found in this sector. However, in the Netherlands there are other (political) reasons to expect domestic natural gas production will shrink in the future. The largest fields have peaked in production and further extraction in these fields causes damages through earthquakes. Drilling for new fields in more ecologically vulnerable regions faces strong opposition from environmental groups. If the Dutch gas sector is projected to shrink over the coming decades, the losses of excluding CCS from the mitigation portfolio are probably limited. The benefits of developing a strong global CCS technology cluster in the CCS scenario have not been modeled in this study. It is uncertain whether such benefits could compensate for the lost employment and GVA the Netherlands. A much more certain advantage of including CCS in the portfolio is the lower $\mathrm{CO}_{2}$ emissions on the medium term. These are important in view of the limited cumulative global $\mathrm{CO}_{2}$ emission budget and the fact that we need to avoid reaching certain triggers in the global

\footnotetext{
${ }^{23}$ Note, the CCS-inclusive strategy has also somewhat more nuclear power than the CCS-exclusive strategy.
} 
climate system. On the other hand it should also be noted that the politically hard won targets for the penetration of renewables in the Netherlands (e.g. [3]) would not be met in the CCS scenario. A final and robust advantage of including CCS is the lower LCOE it would entail. In Koelbl et al. [17] it was shown that the LCOE can be some $12 \%$ lower (causing relatively inelastic energy demand to rise by some 3\%). The upstream, downstream and indirect effects of such lower energy costs and prices, however, cannot be analyzed in an IO-model. Which brings us to the limitations we face with our method of choice.

\subsection{Limitations of the method}

IO-tables cannot account for macro-economic feedback effects and technical change. First, they assume zero elasticity of substitution between goods and production factors. Therefore, the effect of lower electricity cost in the CCS scenario is not accounted for. Second, it is not possible to endogenously model the impacts of policy measures like subsidies, taxes or carbon prices. The electricity prices (and therewith a carbon price) do not have an impact on the production volume or use of energy goods. Similarly, increases in labor demand or imports do not have any impact on wages, exchange rates and other prices. All these second order behavioral responses are excluded from our analysis and may prove quite substantial when price and substitution elasticities are high.

It was possible (as we showed) to treat carbon prices as a tax in the IO-framework. However, this only changes the total direct value added of the power sector (and vice versa for subsidies). The spending of revenues gained by taxes can lead to additional demand and since total emissions in 2030 are higher in the NOCCS scenario this would increase the benefits of this portfolio. Koopmans et al. [7] do state that they assumed subsidies are used to support the deployment of renewable technologies. Due to missing data about technology specific subsidies in their scenarios, however, we were not able to account for that in the value added account of our IO-table calculations. Furthermore, as with taxes, any macroeconomic impacts of financing the subsidies with additional taxation, or by reducing other forms of government consumption, are simply not accounted for in the IO-table. Thus, we recommend repeating this research with a model that can account for macro-economic feedback effects like Computable General Equilibrium (CGE) Models. Such models usually come at the cost of lower sectoral detail and are very sensitive to assumptions, particularly on demand and substitution elasticities that are hard to establish empirically. Moreover, such a fundamentally different approach clearly falls outside the scope of this paper and is left for future research.

In our analysis we make no changes to the total monetary output of electricity as recorded in the IO-table. Thereby we simplify the comparison between the two scenarios. However, this implies that the total (implied) amount of electricity produced differs (only slightly) between the scenarios. As we assume the same LCOE in both scenarios, the deviation in weighted average prices and thus the total production of electricity is very small i.e. less than $1 \%$. However, in studies using energy system models to generate the scenarios, the electricity cost and the power production deviate more strongly between the two scenarios (see e.g. Koelbl et al. [31]). In Koelbl et al. [31] the weighted average electricity cost is about $12 \%$ lower in the CCS scenario and the electricity production by about 3\% higher. Consequently, the total monetary output of power production is around 9\% higher in the NOCCS scenario. For our study this implies that economic impacts of the NOCCS scenario would become somewhat higher and differentials to the CCS scenario for GVA and employment are then likely to be somewhat larger. Also, note that we have developed a method to consistently estimate the final demand for power production within the
IO-framework while keeping total output the same. As upstream effects between the power portfolios differ, final demand will differ. However, this difference turns out to be minimal (less than $1 \%$ ).

The $\mathrm{CO}_{2}$ emission expenses, the assumption on operating surplus and the endogenization of gross fixed capital consumption drive our results for direct GVA from power production. First, expenses on $\mathrm{CO}_{2}$ emissions are higher in the NOCCS scenario. Total amount of GVA classified as tax expenditure is by EUR $1,000,000,000$ higher in the NOCCS scenario. Subtracting this amount from the total GVA differential would change the result, making the GVA slightly higher in the CCS scenario because then the higher upstream results dominate. However, if we keep the assumption that total monetary output of power is the same in the two scenarios, removing the tax expenses from the calculations would not change the result. The GVA differential remains higher in the NOCCS scenario as capital expenses are larger in the NOCCS scenario. Second, if we calculate the results without endogenizing gross fixed capital consumption the GVA differential becomes even larger and GVA results are again higher under the NOCCS strategy. Still, this would considerably decrease the differential in employment between the scenarios as the upstream effects of the higher capital investments associated with construction services would be eliminated. Since the analysis is static and made for a oneyear time frame, we feel it is justified, however to annualize capital costs to increase comparability of technologies. The higher levels of capital investment are an important reason why the renewable technologies have a different impact on the economy than fuel based non-renewable options. Finally, we assume that the cost of financing the capital investments can be treated as operating profits. This also makes the GVA in the NOCCS higher than in the CCS scenario. Eliminating this differential would not change the gap in GVA between the CCS and NOCCS scenario significantly.

\subsection{Limitation of study scope}

Notably, this study is limited to the power sector. Thus economic impacts of mitigation measures outside the power sector are omitted from the results. This excludes, for example, the impacts of investments in end-use efficiency measures. It has been shown in simulation exercises (e.g. Koelbl et al. [31]) that a scenario not allowing for CCS needs higher energy savings and thus more investments in energy saving measures. Because of the relatively high GVA and employment and low import intensity of such efficiency investments, the difference between the CCS and the NOCCS scenario would become larger if we include such measures, making the CCS portfolio an even less favorable strategy for the power sector in the Netherlands.

Focusing exclusively on the power sector also reduces the suitability of the two scenarios. Both scenarios were originally constructed for the whole energy system. Thus, mitigation efforts can be differently distributed over sectors in the two scenarios. Moreover, emission pathways can take a different course until $2050 .{ }^{25}$ A ballpark estimate of emissions ${ }^{26}$ from the power portfolios as proposed by Koopmans et al. [7] for 2030 shows that at this point in time the $\mathrm{CO}_{2}$ emissions from the NOCCS portfolio are higher ${ }^{27}$ (while they are calibrated to be roughly the same in 2050). Thus, more emission reduction efforts must be in place either in another sector for the NOCCS scenario or later in time. From the sensitivity

\footnotetext{
25 Emissions reductions before 2050 are not the same in both scenarios in Koopmans et al. [7].

${ }^{26}$ We use the efficiencies and carbon contents given in Table 2 to calculate emissions from power production.

27 Assuming power production to be around $140 \mathrm{TWh}$ in 2030 [78] in both scenarios and using the carbon contents and efficiencies given in Table 2, emissions are around $11 \mathrm{MtCO}_{2}$ higher assuming 3\% less power production in the NOCCS scenario increases the difference to $12 \mathrm{MtCO}_{2}$.
} 
analysis we can deduct that in 2050, macro-level differences are similar for all three indicators as in 2030 but about three times as strong. This indicates that the tendency of higher GVA and employment as well as lower import dependency of the NOCCS scenario is robust on the macro-level. Nevertheless, we recommend further research looking at the whole target period and including all sectors. Such extensions could be made by repeating the IO-analysis presented here for all years or by building a dynamic simulation model based on CGE. Again, we deem this beyond the scope of the present paper.

A final, important limitation in the scope concerns the potential economic impacts for the Netherlands arising from developing a competitive advantage and thus gaining market shares in the global CCS market. For example, Koornneef et al. [6] consider this a considerable additional benefit and cumulatively over the period between 2010 and 2050 they estimate that the value added generated by Dutch companies due to their competitive advantage in the CCS sector could add up to EUR 13,000,000,000. However, they do not compare these results to value added that could be gained by Dutch companies from gaining global market shares in renewable technologies if the emphasis in the Dutch energy sector is shifted towards those technologies. The presented IO-analysis cannot account for such comparative advantage and technological change dynamics. We feel that, although such considerations are important, they are intrinsically hard to quantify and model, even in more advanced simulation models. In the end, such predictions are surrounded with such high levels of uncertainty that results become highly speculative.

\subsection{Limitation of scenario availability}

The portfolios for power production suggested in Koopmans et al. [7] are two reasonable outcomes for the future power mix in the Netherlands. But of course one could argue there are many more. They are based on assumptions of technology availability, potentials and technological development. However, such assumptions are surrounded by uncertainty and these scenarios are not a result of a cost optimization exercises. Therefore, the power mix in both scenarios may be different which could change the results of this study. For example, the share of renewable power in the two portfolios could be larger given that the Netherlands has set a target for renewable energy in 2023 of $16 \%$ [64]. Especially in the CCS scenario the share of renewables in 2030 is only $13 \%$. Therefore, we conducted a sensitivity analysis were we increase the share of renewable power in both scenarios. The results show that the differences between the two scenarios for the three indicators on the macro-level become somewhat less pronounced. The tendency is however the same. The scenarios analyzed here are not intended to be actual predictions. Instead we chose these scenarios as consistent and published alternatives that are representative of a future with and without CCS.

The CCS scenario from Koopmans et al. [7] does not foresee CCS in combination with Biomass (BECCS). Because of its potential to produce negative emissions, BECCS can be an important mitigation tool under stringent mitigation targets [71-73]. A similar study for Europe indicates that BECCS can increase gross employment impacts via domestic bio-energy production [31]. These effects are unlikely to tip the balance of gross employment impacts for the CCS strategy in the Netherlands, as potentials for bio-energy production are limited in the Netherlands. Thus, higher bioenergy use in the CCS scenario than in the NOCCS scenario is unlikely to significantly increase domestic production (and thus employment and GVA) of bio-energy but rather increase import dependency. It is however, likely that such imports could be sourced from a diverse portfolio of reliable trading partners, which is less likely for natural gas.

\subsection{Limitation in data sources}

One of the main objectives of developing EXIOBASE was to create a very detailed, global multi-regional system of supply-use and input-output tables and to integrate as much as possible environmental data regarding emissions, energy, materials, water, land and waste into the SUT/IOT framework. With this global perspective in mind EXIOBASE is very well suited for global analysis of resource use and emissions issues, including simultaneous assessment of production- and consumption-based environmental indicators for nations and groups of nations. However, the specific input and output structures of detailed sectors and products are not always represented with a high level of accuracy. Except for the total output levels, it would be misleading to directly use EXIOBASE in order to draw conclusions about relative efficiencies of different technologies or to compare between countries' input structures of sectors that went through the disaggregation procedure. The reason behind it is that EXIOBASE is mainly based on the public and official statistical sources with good geographical coverage. These sources, however, often lack detailed sectoral information. In case of a sector-specific research question, as in this paper, it is important that a researcher crosschecks other national sources and/or specialized sector studies and adjusts the data if necessary. In this research we therefore adjusted the input vectors for power production in the Netherlands based on technoeconomic data for the Netherlands. The data was used to calculate cost shares of six categories (see Tables 2 and 3), which were then further distributed over supplying sectors based on the detailed distribution in EXIOBASE as described in Table 3. In that way we make sure that for instance fuel supply coefficients are consistent with future assumptions about efficiency and prices. Furthermore, we exclude input coefficients such as pipeline transport services from technologies that are unlikely to make use of this service (e.g. nuclear, biomass, coal and renewable power production). However, conclusions from detailed sector results should be drawn with the utmost caution and need further robustness checks using detailed and more precise data.

Finally, the discount rates to annualize the capital cost and to calculate the financing cost were set to $10 \%$ for all technologies. However, discount rates differ between technologies and sectors. In fact, they even differ between companies in sectors. This would mostly influence the amount of value added per technology as the capital financing cost change depending on the discount rate. Oxera Consulting Ltd [35] give projected discount rates for future power generation technologies which we used in order to test the sensitivity of the macro-level results. The results show that results remain qualitatively similar. Quantitatively the differential in GVA and import dependency decreases whereas the difference in total employment impacts increases. We chose to present the results for an identical discount rate not to confound our main effects here.

\section{Conclusions}

In this study, we made a socio-economic (what-if) analysis for two different low-carbon power production portfolios suitable for the Netherlands around the year 2030. We compared GVA, gross employment and import dependency impacts of a power mix with and without carbon capture and storage. For this we used bottom-up technology data (LCOE) and a macro-economic IO-table (EXIOBASE). In order to integrate the 2030 projection of power production technology shares into a 2007 Input-Output table database, we developed a method to consistently estimate final demand for power production within the IO-framework. This is especially useful when IO-tables need to be linked with technoeconomic energy system models to look at future energy 
consumption as these models may not project final demand of energy consumption separately from intermediate demand.

The comparison of the scenarios is static, and effects on the macro-level are only partial effects as macro-economic feedbacks are not included. Still, the results provide a first indication of the wider socio-economic impacts of including or excluding CCS in the power sector in the Netherlands to mitigate carbon dioxide emissions especially for the sector level. The major difference between the scenarios is the share of nuclear and thermal fossil fuel plants (coal \& natural gas) and the share of renewables (wind and bio-energy) in power production for 2030. Differences for individual sectors can be considerable. On the aggregate national level, however, results are modest in comparison to the macro-economic totals in 2007.

Sector-level results suggest that the sector providing construction work is affected notably by the choice between the two scenarios. While for GVA the direct impacts are most important, for employment upstream market differences are largest for construction services. The latter is higher in the NOCCS scenario due to the higher construction demand for renewable power production. This difference can become more severe with a larger share of renewables in the NOCCS scenario and a larger share of coal CCS in the CCS scenario (which is suggested by the power portfolio projections for 2050).

As natural gas power plays a larger role in the CCS portfolio, GVA and employment in gas mining and for gas distribution services are higher for this strategy. However for natural gas the strong difference between the scenarios is alleviated when we take into account larger import shares of natural gas in the future. Although, there are also notable differences between the portfolio compositions with respect to coal power, this does not make a difference for GVA and employment on the sector level within the Netherlands. Since coal is imported, the difference appears outside of the European Union.

In the upstream sectors the difference between the CCS and the NOCCS scenario is more important for employment than for GVA. First, upstream employment is higher in the NOCCS scenario than in the CCS scenario and the opposite is the case for GVA. This is largely because the additional jobs from construction in the NOCCS scenario dominate the national upstream difference in employment, while GVA in natural gas mining dominates the difference in GVA between the scenarios in the upstream sectors. Second, the difference in employment for construction is higher by a factor of 16 than the negative difference in the mining sector, while the GVA difference in the mining sector is only about 3 times as high as in the construction sector. This implies that the relative difference for the upstream markets is more significant for employment.

The partial effect on total gross value added in the Netherlands is somewhat lower in the CCS scenario. The difference in GVA is small compared to the total GVA in the Netherlands, but compared to GVA from power production it is a substantial amount. The dominating factor in the GVA difference is the larger amount of expenses on carbon emissions in the NOCCS scenario as emissions from this portfolio are higher in 2030. Under historical import shares of natural gas, upstream impacts for GVA are higher in the CCS scenario than in the NOCCS scenario. However, this was shown to depend on the assumptions regarding natural gas imports.

The partial effect on employment in the Netherlands is somewhat less employment in the CCS scenario than in the NOCCS scenario. Gross employment is lower in the CCS scenario, as for GVA. Again, in comparison to the total workforce in 2007, the impact is small $(0.07 \%)$, but it makes about $45 \%$ of employment from power production in 2007. The difference in direct employment plays a much smaller role here than the difference in employment from upstream demands. The difference is largely due to the strong difference in employment intensity of the most impacted upstream markets. In fact, the major difference is made by fuel inputs (natural gas) with low employment intensity but high use in the CCS scenario and capital inputs (construction services), which are employment intensive and in higher demand for renewable power production.

The CCS scenario leads to a higher dependency on imports of coal and, to a lesser degree, natural gas from outside Europe. Total imports are around EUR 776,000,000 higher when using the CCS power portfolio. This difference makes $0.4 \%$ of the total imports in the 2007 IO-table, and is as high as $23 \%$ of the imports to power production in 2007. The higher import dependency is mainly a result of the higher use of coal and natural gas from outside Europe. Because this leads mostly to higher coal imports, the consequence for energy security is small given the fact that coal is produced in a large number of countries. However, if import shares of natural gas would become more important, the energy security impacts could be more severe.

Expected higher natural gas imports in the future amplify differences in macro-results, and aggravate import dependency. We found that total GVA, employment and import differences have the same sign but become larger if import shares of natrual gas for power production are increased. Still, while upstream results for GVA are higher in the CCS scenario under the trade structure of 2007, increasing the natural gas import shares to $60 \%$ changes the sign of upstream results. Then they are somewhat higher in the NOCCS scenario, as natural gas is comparatively GVA intensive. Additionally, higher natural gas imports increase the import dependency and have adverse implications for energy security as natural gas supply is regionally less diversified.

The sensitivity analysis shows that results become stronger with larger deviations in technology shares between the scenarios in 2050. As the shares of renewables increase in the NOCCS portfolio while shares of coal with CCS are higher in the CCS strategy in order to meet the emission reduction target in 2050, we find that macro-level results become more pronounced. The difference in total intermediate imports from outside Europe and GVA is more than three times as high as for the 2030 portfolio comparison, and the difference in employment is about five times as high. Also, upstream GVA in the CCS scenario becomes less than in the NOCCS scenario. The driving force behind these findings are the higher domestic production inputs to renewable technologies in the NOCCS scenario as opposed to the higher imports for coal fired power with CCS. This means that, in comparison to the renewable-based scenario, coal imports shift upstream impacts abroad in contrast to renewable power where IO-table data suggests high shares of domestically produced construction and business services.

While the results provide a first indication of impacts of a CCS versus a no-CCS case, the results have to be interpreted against the background of the scenarios. Key limitations we pointed out are (1) the exclusive focus on the power sector which excludes the impacts of measures in other sectors, (2) the higher emission reductions in the CCS scenario within the power sector in 2030 , (3) the exclusion of energy saving measures, (4) the missing price effects and (5) the lacking availability of precise input data to specific power production options on the level of product resolution given by the IO-table. However, some of the conclusions are indicative for other scenarios and the results can be used in order to get an estimate of how impacts might change for other scenarios.

Further research should be done (1) using a macro-economic model that can account for feedback effects (2) using a scenario that includes the whole energy system and (3) gather improved 
technology specific input data with a high product/supply sector resolution. Since IO-tables cannot take into account macroeconomic feedback effects from price changes or policies it would be crucial to explore how results would change if such feedbacks are considered. We also discussed that our analysis cannot lead to strong conclusions as long as it is conducted only for the isolated power sector. Therefore, results need to be validated in a model study that can account (at least) for the whole energy system. Finally, with respect to sector results we have shown a method in order to alleviate the possible bias from the generic data construction for the IO-table. However, this mostly covers the level of detail of the LCOE cost components shown in the method section. To make solid conclusions on the sector level, it is crucial to invest in data collection with a high level of detail for these technologies.

The advantage of our method over these more elaborate and precise modeling exercises, however, is that the IO-Model allows for very high sectoral resolution and has the important benefit of being fully tractable. Our simulation is not intended to yield very precise predictions, but it very clearly shows where the quantitatively most important effects are to be expected in a transition to a more climate neutral energy system with and without CCS.

\section{Acknowledgements}

This research has been carried out in the context of the CATO-2program. CATO-2 is the Dutch national research program on $\mathrm{CO}_{2}$ Capture and Storage. The program is financially supported by the Dutch government (Ministry of Economic Affairs) and the CATO2 consortium parties. We would also like to thank Dr. Evgueni V. Poliakov (TNO) and Dr. Walter Manshanden (TNO) for their help and contribution to the method of this research. And we thank Dietmar Edler for consultation on data collection for the input structure of power technologies. Furthermore, we would like to thank Stefan Berrelkamp for the preliminary inquiry of this topic.

\section{Appendix A. Supplementary material}

Supplementary data associated with this article can be found, in the online version, at http://dx.doi.org/10.1016/j.apenergy.2016. 08.068.

\section{References}

[1] Ministry of Infrastructure and the Environment. Klimaatagenda: weerbaar, welvarend en groen. Den Haag (the Netherlands); 2013.

[2] UNFCCC. Adoption of the Paris Agreement. Proposal by the President. Draft decision -/CP.21. Paris (France): United Nations Framework Convention on Climate Change; 2015.

[3] SER. Energieakkoord voor duurzame groei. Den Haag, The Netherlands: Sociaal-Economische Raad; 2013.

[4] PBL, ECN. Naar een schone economie in 2050: routes verkend Hoe Nederland klimaatneutraal kan worden. Den Haag, the Netherlands: Planbureau voor de Leefomgeving (PBL), Energieonderzoek Centrum Nederland (ECN); 2011.

[5] van Alphen K. Accelerating the development and deployment of carbon capture and storage technologies - an innovation system perspective. Utrecht University: Copernicus Institute for Sustainable Development and Innovation; 2011.

[6] Koornneef J, Hendriks C, Noothout P, Smith M. Social costs and benefits of CCS research, development and deployment for the Dutch economy. Utrecht (Netherlands): Ecofys; 2014.

[7] Koopmans C, Tieben B, van den Berg M, Willebrands D. Investeren in een schone toekomst: De kosten en baten van een duurzame energiehuishouding in Nederland. Amsterdam (The Netherlands): SEO Economisch Onderzoek; 2010.

[8] Arto I, Rueda-Cantuche JM, Andreoni V, Mongelli I, Genty A. The game of trading jobs for emissions. Energy Policy 2014;66:517-25. http://dx.doi.org/ 10.1016/i.enpol.2013.11.046.

[9] Shammin MR, Bullard CW. Impact of cap-and-trade policies for reducing greenhouse gas emissions on U.S. households. Ecol Econ 2009;68:2432-8. http://dx.doi.org/10.1016/j.ecolecon.2009.03.024.
[10] AEA. Future Value of Carbon Abatement Technologies in Coal and Gas Power Generation to UK Industry. Didcot, Oxfordshire: AEA Technology plc; Final report to the Department of Energy and Climate Change; 2010.

[11] AEA. Future value of coal carbon abatement technologies to UK industry. Didcot (Oxfordshire): AEA Technology plc; Final report to the Department of Energy and Climate Change; 2008.

[12] Jeavons D, Marchetti J, Cichanowicz E, Hein M. Employment and other economic benefits from advanced coal electric generation with carbon capture and storage (preliminary results). American Coalition for Clean Coal Electricity. Denver, Colorado/USA.: BBC Research \& Consulting prepared for Industrial Union Council, AFL-CIO; International Brotherhood of Boilermakers, Iron Ship Builders, Blacksmiths, Forgers, and Helpers; International Brotherhood of Electrical Workers; United Mine Workers of America; 2009.

[13] Scottish Enterprise AEA. Economic impact assessments of the proposed carbon capture and storage demonstration projects in Scotland - a Summary report. Glasgow: Scottish Enterprise, AEA; 2011.

[14] Wei M, Patadia S, Kammen DM. Putting renewables and energy efficiency to work: how many jobs can the clean energy industry generate in the US? Energy Policy 2010;38:919-31. http://dx.doi.org/10.1016/i.enpol.2009.10.044.

[15] Viebahn P, Daniel V, Samuel H. Integrated assessment of carbon capture and storage (CCS) in the German power sector and comparison with the deployment of renewable energies. Appl Energy 2012;97:238-48. http://dx. doi.org/10.1016/j.apenergy.2011.12.053.

[16] Viebahn P, Vallentin D, Höller S. Prospects of carbon capture and storage (CCS) in China's power sector - an integrated assessment. Appl Energy 2015;157:229-44. http://dx.doi.org/10.1016/i.apenergy.2015.07.023.

[17] Stamford L, Azapagic A. Life cycle sustainability assessment of UK electricity scenarios to 2070. Energy Sustain Develop 2014;23:194-211. http://dx.doi. org/10.1016/i.esd.2014.09.008.

[18] Capros P, Paroussos L, Fragkos P, Tsani S, Boitier B, Wagner F, et al. European decarbonisation pathways under alternative technological and policy choices: a multi-model analysis. Energy Strategy Rev 2014;2:231-45. http://dx.doi.org/ 10.1016/i.esr.2013.12.007.

[19] Choi J-K, Bakshi BR, Hubacek K, Nader J. A sequential input-output framework to analyze the economic and environmental implications of energy policies: gas taxes and fuel subsidies. Appl Energy 2016. http://dx.doi.org/10.1016/j. apenergy.2016.05.033.

[20] Behrens P, Rodrigues JFD, Brás T, Silva C. Environmental, economic, and social impacts of feed-in tariffs: a Portuguese perspective 2000-2010. Appl Energy 2016;173:309-19. http://dx.doi.org/10.1016/i.apenergy.2016.04.044.

[21] Markandya A, Arto I, González-Eguino M, Román MV. Towards a green energy economy? Tracking the employment effects of low-carbon technologies in the European Union. Appl Energy 2016. http://dx.doi.org/10.1016/j. apenergy.2016.02.122.

[22] Yushchenko A, Patel MK. Contributing to a green energy economy? A macroeconomic analysis of an energy efficiency program operated by a Swiss utility. Appl Energy 2016. http://dx.doi.org/10.1016/i.apenergy.2015.12.028.

[23] CPB, MNP, RBP. Energie. Welvaart en Leefomgeving, een scenariostudie voor Nederland in 2040, achtergronddocument, Den Haag: Centraal Planbureau, Milieu- en Natuurplanbureau en Ruimtelijk Planbureau; 2006. p. 257-314.

[24] CPB, MNP, RBP. Welvaart en leefomgeving een scenariostudie voor Nederland in 2040. Den Haag: Centraal Planbureau, Milieu- en Natuurplanbureau en Ruimtelijk Planbureau; 2006.

[25] IEA. Energy technology perspectives 2010: scenarios and strategies to 2050. Paris: International Energy Agency, OECD Publishing; 2010.

[26] Schoots K. Innovatie en leercurven Rapportage naar aanleiding van kennisvragen Werkgroep Energie en Klimat Verantwoording. Energieonderzoek Centrum Nederland (ECN); 2010.

[27] statline.cbs.nl. CBS StatLine - Electricity and heat; production and input by Energy Co... 2015:80030 <http://statline.cbs.nl/Statweb/publication/?DM= SLEN\&PA=80030eng\&D1=0-3\&D2=0\&D3=0,2-5,7-12\&D4=15\&LA=EN\&HDR=T\& $\mathrm{STB}=\mathrm{G} 1, \mathrm{G} 2, \mathrm{G} 3 \& \mathrm{VW}=\mathrm{T}>$ [accessed December 14, 2015].

[28] Wood R, Bulavskaya T, Ivanova O, Stadler K, Simas M, Tukker A, et al. Report D7.2: Update EXIOBASE apart from WP3-6 input. Revision number 1.0; 2013.

[29] Wood R, Stadler K, Bulavskaya T, Lutter S, Giljum S, de Koning A, et al. Global sustainability accounting-developing EXIOBASE for multi-regional footprint analysis. Sustainability 2015;7:138-63. http://dx.doi.org/10.3390/su7010138.

[30] Wood R, Hawkins TR, Hertwich EG, Tukker A. Harmonising national inputoutput tables for consumption-based accounting - experiences from Exiopol. Econ Syst Res 2014;26:387-409. http://dx.doi.org/10.1080/ 09535314.2014.960913.

[31] Koelbl BS, Wood R, van den Broek MA, Sanders MWJL, Faaij APC, van Vuuren DP. Socio-economic impacts of future electricity generation scenarios in Europe: Potential costs and benefits of using CO2 Capture and Storage (CCS). Int J Greenhouse Gas Control 2015;42:471-84. http://dx.doi.org/10.1016/i. ijggc.2015.08.010.

[32] IEA, NEA, OECD. Projected Costs of Generating Electricity 2010 Edition. Paris, France: International Energy Agency (IEA)/Nuclear Energy Agency (NEA)/ Organisation for Economic Co-operation and Development (OECD); 2010. doi: http://dx.doi.org/10.1787/9789264084315-en.

[33] Deutch JM, Forsberg CW, Kadak AC, Kazimi MS, Moniz EJ, Parsons JE, et al Update of the MIT 2003 future of nuclear power. Massachusetts Institute of Technology (MIT); 2009.

[34] NETL. Cost and Performance Baseline for Fossil Energy Plants Volume 1: Bituminous Coal and Natural Gas to Electricity. vol. 1. Revision 2. National Energy Technology Labratory (NETL)/US Department of Energy; 2010. 
[35] Oxera Consulting Ltd., Discount rates for low-carbon and renewable generation technologies. Oxford, UK; Brussels, Belgium; London, UK: Prepared for the Committee on Climate Change; 2011.

[36] NETL. Role of Alternative Energy Sources: Nuclear Technology Assessment. National Energy Technoloy Labratory (NETL); 2012.

[37] Lako P. Biomass for heat and power. Technology Brief E05 - May 2010. IEA/ ETSAP 2010;1-8 <http://iea-etsap.org/web/E-TechDS/PDF/E05-BiomassforHPGS-AD-gct.pdf $>$ [accessed November 3, 2015].

[38] Verdonk M, Wetzels W. Referentieraming energie en emissies: actualisatie 2012; Energie en emissies in de jaren 2012, 2020 en 2030. Den Haag, the Netherlands: Planbureau voor de Leefomgeving (PBL), ECN; 2012.

[39] Phyllis2 - ECN. coal, Polish bituminous coal (\#1272),Phyllis2 - ECN Phyllis classification. Energy Research Centre of the Netherlands 2012:2015<https:/ www.ecn.nl/phyllis2/Browse/Standard/ECN-Phyllis\# [accessed October 27, 2015]

[40] Phyllis2 - ECN. Groningen natural gas, Phyllis2 - ECN Phyllis classification. Energy Research Centre of the Netherlands 2012:2015 <https://www.ecn. nl/phyllis2/Browse/Standard/ECN-Phyllis\# [accessed October 27, 2015].

[41] Bates J, Henry S. Carbon factor for wood fuels for the Supplier Obligation Final report. AEA/ED01858010/Issue 2. Didcot: AEA Technology plc; 2009.

[42] Phyllis2 - ECN. Phyllis2 - ECN Phyllis classification. Energy Research Centre of the Netherlands 2012:2-4 <https://www.ecn.nl/phyllis2/Browse/Standard/ ECN-Phyllis\# [accessed January 21, 2016].

[43] GCCSI. Economic Assessment of Carbon Capture and Storage Technologies 2011 update. Canberra, Australia: 2011.

[44] van den Broek M, Hoefnagels R, Rubin E, Turkenburg W, Faaij A. Effects of technological learning on future cost and performance of power plants with $\mathrm{CO}_{2}$ capture. Prog Energy Combust Sci 2009;35:457-80. http://dx.doi.org/ 10.1016/i.pecs.2009.05.002.

[45] Brouwer AS, van den Broek M, Seebregts A, Faaij A. Operational flexibility and economics of power plants in future low-carbon power systems. Appl Energy 2015;156:107-28. http://dx.doi.org/10.1016/j.apenergy.2015.06.065.

[46] Brouwer AS, Van den Broek M, Zappa W, Turkenburg WC, Faaij A. Least-cost options for integrating intermittent renewables in low-carbon power systems. Appl Energy 2016;161:48-74. http://dx.doi.org/10.1016/i. apenergy.2015.09.090

[47] IEAGHG. Appendix E Factsheet Biomass (co-)firing for power generation. Potential for biomass and carbon dioxide capture and storage, Stoke Orchard, UK: International Energy Agency Greenhouse Gas R\&D Programme (IEAGHG); 2011, p. 181-72.

[48] IEA. World Energy Investment Outlook. Paris Cedex, France: International Energy Agency (IEA); 2014.

[49] IHS. IHS Indexes: European Power Capital Cost Index (EPCCI) $2014<$ http:// www.ihs.com/info/cera/ihsindexes/index.aspx> [accessed January 1, 2014].

[50] OECD.stat. CPI energy OECD region 2015 <http://stats.oecd.org/index.aspx? DatasetCode=MEI_PRICES $>$ [accessed October 27, 2015].

[51] NETL. Quality Guidlines for Energy System Studies: Cost Estimation Methodology for NETL Assessments of Power Plant performance. vol. DOE/NETL-2. National Energy Technology Labratory (NETL)/US Department of Energy; 2011.

[52] Londo M, Plomp A, Beurskens L, Hekkenberg M, Mozaffarian H, Taris A-M, et al. Eindadvies basisbedragen SDE+ 2015. Petten: ECN, DNV GL, TNO; 2014.

[53] Goh CS, Junginger M. Sustainable biomass and bioenergy in the Netherlands: Report 2014. Utrecht, The Netherlands: This study was carried out in the framework of the Netherlands Programmes Sustainable Biomass by Copernicus Institute, Utrecht University; 2015.

[54] Elbersen B, Staritsky I, Hengeveld G, Jeurissen L, Lesschen J-P. Outlook of spatial biomass value chains in EU 28. 2015.

[55] OECD.stat. Consumer Price Index Energy - OECD Total $2014<$ http://stats.oecd. org/index.aspx? DatasetCode=MEI_PRICES\#> [accessed September 22, 2014].

[56] Oanda. Historical Exchange Rates. Currency Converter 2014:1-2 <http://www. oanda.com/currency/historical-rates/> [accessed July 15, 2014].

[57] Leontief WW. Quantitative input and output relations in the economic systems of the United States. Rev Econ Statist 1936;18:105-25.

[58] Leontief W. Input-output economics. 2nd pri. New York: Oxford University Press; 1966.

[59] Malik A, Lenzen M, Ely RN, Dietzenbacher E. Simulating the impact of new industries on the economy: the case of biorefining in Australia. Ecol Econ 2014;107:84-93. http://dx.doi.org/10.1016/i.ecolecon.2014.07.022.
[60] Tertrais B. DIIS policy brief: uranium from Niger: a key resource of diminishing importance for France. Copenhagen (Denmark): Danish Institute for International Studies (DIIS); 2014 <https://www.ciaonet.org/attachments/ 25248/uploads> [accessed 14.01.16];:

[61] World Nuclear Association. Nuclear Power in France 2016:1-19 <http:// www.world-nuclear.org/information-library/country-profiles/countries-a-f/ france.aspx> [accessed February 23, 2016].

[62] van 't Hof W. (Future) role of natural gas in the Netherlands 2015:16 <https:// www.unece.org/fileadmin/DAM/energy/se/pp/geg/geg2_jan2015/ai10 3_vantHOF.pdf> [accessed November 20, 2015].

[63] Honoré A. The outlook for natural gas demand in Europe. OIES PAPER: NG 87. The Oxford Institute for Energy Studies, University of Oxford; 2014.

[64] IEA. Executive summary and key recommendations. Energy policies of IEA countries: The Netherlands: 2014 review, Paris and Washington, DC: International Energy Agency; 2014, p. 9-14.

[65] Groenenberg H, de Coninck H. Effective EU and member state policies for stimulating CCS. Int J Greenhouse Gas Control 2008;2:653-64. http://dx.doi. org/10.1016/j.ijggc.2008.04.003.

[66] de Coninck H, Flach T, Curnow P, Richardson P, Anderson J, Shackley S, et al. The acceptability of $\mathrm{CO}_{2}$ capture and storage (CCS) in Europe: An assessment of the key determining factors: Part 1. Scientific, technical and economic dimensions. Int J Greenhouse Gas Control 2009;3:333-43.

[67] Shackley S, Reiner D, Upham P, de Coninck H, Sigurthorsson G, Anderson J. The acceptability of $\mathrm{CO}_{2}$ capture and storage (CCS) in Europe: An assessment of the key determining factors. Part 2 . The social acceptability of CCS and the wider impacts and repercussions of its implementation. Int J Greenhouse Gas Control 2009;3:344-56. http://dx.doi.org/10.1016/j.ijggc.2008.09.004.

[68] Johnsson F, Reiner D, Itaoka K, Herzog H. Stakeholder attitudes on carbon capture and storage-an international comparison. Int J Greenhouse Gas Control 2010;4:410-8. http://dx.doi.org/10.1016/i.ijggc.2009.09.006.

[69] Terwel BW, Harinck F, Ellemers N, Daamen DDL. Going beyond the properties of $\mathrm{CO}_{2}$ capture and storage (CCS) technology: how trust in stakeholders affects public acceptance of CCS. Int J Greenhouse Gas Control 2011;5:181-8. http:// dx.doi.org/10.1016/i.ijggc.2010.10.001.

[70] IEA. A policy strategy for carbon capture and storage, Paris: International Energy Agency (IEA); 2012, p. 1-56.

[71] Azar C, Lindgren K, Obersteiner M, Riahi K, Vuuren DP, Elzen KMGJ, et al. The feasibility of low $\mathrm{CO}_{2}$ concentration targets and the role of bio-energy with carbon capture and storage (BECCS). Climatic Change 2010;100:195-202. http://dx.doi.org/10.1007/s10584-010-9832-7.

[72] Koelbl BS, van den Broek MA, Faaij APC, van Vuuren DP. Uncertainty in Carbon Capture and Storage (CCS) deployment projections: a cross-model comparison exercises. Climatic Change 2014;123:461-76. http://dx.doi.org/10.1007/ s10584-013-1050-7.

[73] van Vuuren DP, Deetman S, van Vliet J, van den Berg M, van Ruijven B, Koelbl $\mathrm{BS}$. The role of negative $\mathrm{CO}_{2}$ emissions for reaching $2{ }^{\circ} \mathrm{C}-$ insights from integrated assessment modelling. Climatic Change 2013;118:15-27. http://dx. doi.org/10.1007/s10584-012-0680-5.

[74] EXIOBASE. EXIOBASE2 (year 2007) full data set 2015. http://www.exiobase.eu/ index.php/data-download/exiobase2-year-2007-full-data-set.

[75] OECD. Looking to 2060: A global vision of long-term growth. Paris (France): OECD Economics Department Policy Notes NO. 15. November 2012. Organisation for Economic Co-operation and Development (OECD); 2012.

[76] Euorstat. Eurostat manual of supply, use and input-output tables. 2008th ed. Luxembourg: European Commission; 2008.

[77] UN. Studies in methods handbook of national accounting handbook of inputoutput table compilation and analysis. New York (NY, USA): United Nations, Department for Economic and Social Affairs Statistics Division Studies; 1999.

[78] Rooijers FJ, Schepers BL, van Gerwen, Rob JF, van der Veen W, Verheij F, de Buck A, et al. Scenario-ontwikkeling energievoorziening 2030. Delft, The Netherlands: Publicatienummer: 14.3C93.34, Opdrachtgever: Netbeheer Nederland, CE Delft, DNV GL; 2014.

[79] OECD.stat. CPI OECD Europe 2016 <http://stats.oecd.org/index.aspx? DatasetCode=MEI_PRICES\#> [accessed January 20, 2016]. 